\title{
La educación científica en el currículo oficial de Primaria para Andalucía: Un análisis crítico ${ }^{1}$
}

\author{
Antonio García-Carmona, Ana M. Criado y Pedro Cañal Universidad de Sevilla*
}

RESUMEN: Se presentan los resultados de un análisis crítico, de corte interpretativo, sobre la educación científica que se promueve desde el curriculum oficial de Primaria para Andalucía. Para ello, se aplicó un protocolo de análisis, ya validado por los autores en estudios anteriores, que integra una relación de estándares o posicionamientos predominantes en la Didáctica de las Ciencias actualmente. Como estrategia de fiabilidad, el análisis se hizo combinando procesos inter- e intra-jueces. Los resultados revelan que la educación científica sugerida oficialmente para Andalucía no sintoniza, en cierta medida, con las actuales tendencias en Didáctica de las Ciencias. A la vista de las carencias detectadas, se hacen algunas recomendaciones que mejorarían la propuesta oficial, al respecto.

Palabras clave: Andalucía; Ciencia escolar; Curriculum oficial; Educación científica; Educación Primaria.

ABSTRACT: Science education in the Andalusia's official curriculum for Primary Education: a critical analysis.

Science education promoted by Andalusia's official curriculum for Primary Education is analyzed by means of a critical and interpretative analysis. For this aim a protocol validated previously by the authors is applied. The protocol includes a set of standards referred to the current trends in science education. As a reliability strategy, the protocol was applied by means of both interjudge and intrajudge analysis methods. Results reveal that science education suggested for Primary Education in Andalusia does not completely fit with current trends in science education. In view of the weaknesses detected in the document, several recommendations are made in order to improve it.

KeYwords: Andalusia; Official curriculum; Primary Education; Science education; School science.

RÉSUMÉ: L'enseignement des sciences dans le primaire du programme officiel pour l'Andalousie: une analyse critique.

Nous présentons les résultats d'une analyse critique et interprétative sur l'enseignement des sciences qui est promu dans le programme officiel de l'enseignement primaire en Andalousie. Pour ce faire, nous avons appliqué un protocole d'analyse, et validé par les auteurs dans des études précédentes, qui comprennent une liste des positions standard ou dominante dans la formation des connaissances scientifiques actuelles. Comme stratégie de fiabilité, l'analyse a été faite en combinant des processus inter-juges et intra-juges. Les résultats révèlent que l'enseignement des sciences de l'Andalousie officiellement suggéré de ne pas accorder une certaine mesure, avec les tendances actuelles dans l'enseignement des sciences. Compte tenu des lacunes identifiées, des recommandations sont faites pour améliorer la proposition formelle à cet égard.

Mots clé: Andalousie; La science école; Programme officiel; L'enseignement des sciences; L'enseignement primaire.

1 Este trabajo es resultado del Proyecto I+D: ¿Cómo mejorar la enseñanza elemental sobre el medio?: análisis del currículo, Ios materiales y la práctica docente. EDU2009-12760EDUC (2009-2012), financiado por Ministerio de Ciencia e Innovación. Y del Proyecto de Excelencia: ¿Cómo se realiza la enseñanza sobre la realidad social y natural en las aulas de Educación Infantil y Primaria de Andalucía? Estudio de las estrategias didácticas y propuestas de mejora. SEJ-5219 (2010-2014), financiado por la Junta de Andalucía y Fondos FEDER.

" Departamento de Didáctica de las Ciencias. Universidad de Sevilla.

Correos electrónicos: garcia-carmona@us; acriado@us.es; pcanal@us.es

$\bowtie$ Artículo recibido el 15 de Julio de 2013 y aceptado el 24 de Enero de 2014. 


\section{Introducción}

El reciente informe Enciende (COSCE 2011) advierte de la urgente necesidad de promover, en España, una adecuada educación científica desde edades tempranas (3 a 16 años). Ello es consecuencia de los resultados de la úl tima prueba de evaluación PISA, que sitúan a país por debajo del nivel deseable. Para la mejora, el informe hace recomendaciones relativas a enfoques y estrategias educativas, formación del profesorado, acercamiento de la comunidad científica a la escolar, y, en general, a la promoción de la cultura científica en la sociedad.

A nivel europeo, el informe de la fundación Nuffield (Osborne y Dillon, 2008) indica que, pese a las continuas reformas curriculares para renovar la educación científica, su implementación en las aulas sigue siendo fundamentalmente propedéutica. Frente a ello, insiste en impulsar en las aulas una alfabetización científica básica para todos.

El informe de Rocard et al. (2007) también denuncia la preocupante situación actual de la educación científica en Europa. Propone para ello, procesos educativos que impulsen e aprendizaje de la Ciencia como investigación de modo que centra, igualmente, sus críticas en las malogradas implementaciones de las prescripciones del currículo de Ciencia en las aulas.

Por tanto, estos informes ponen el foco, esencialmente, en los profesores, los enfoques las estrategias de enseñanza. Pero no inciden en las disposiciones y recomendaciones de los $\mathrm{cu}$ rrículos oficiales de Ciencia escolar, para cuestionar si son las más adecuadas y si, de algun manera, pueden estar también dificultando la alfabetización científica en las aulas.

El informe Eurydice (2011) sí se detiene en las últimas reformas curriculares de Ciencia en los países de la UE. Revisa las novedades más notorias de cada una de ellas, y destaca el compromiso generalizado por una educación científica basada en el desarrollo de competencias. Si bien, la revisión no permite obtener conclusiones de fondo sobre las fortalezas y carencias de los nuevos currículos para con la alfabetización científica deseable.
Ciertamente son escasos los estudios que analizan directamente los currículos oficiales de Ciencia; si bien los existentes revelan carencias en los mismos. García et al. (2002) analizaron cómo el currículo oficial argentino fomenta el aprendizaje de las estrategias de razonamiento y de argumentación en niveles de Primaria y Secundaria. Concluyeron que los procedimientos que, según la investigación didáctica, suelen favorecer tales estrategias no son prescritos convenientemente.

En España destacan dos estudios sobre la educación científica prescrita en el currículo oficial LOE para Primaria. El primero (De Pro y Miralles, 2009) analiza la incorporación de las competencias como elemento novedoso, así como la sintonía de los objetivos, contenidos y criterios de evaluación con las tendencias actuales en Didáctica de las Ciencias. El segundo (Banet, 2010) examina, además de ello, las orientaciones del mismo documento para la educación científica inicial, comparando sus novedades respecto a los currículos oficiales precedentes (LOGSE y LOCE). Ambos estudios concluyen que el documento presenta carencias significativas para favorecer el inicio de la alfabetización científica en la etapa de Primaria.

Para profundizar en ello, García-Carmona et al. (2014) han analizado también las prescripciones oficiales de la LOE para la educación científica en Primaria, considerando un mayor número de aspectos. Además de corroborar las deficiencias detectadas en los estudios anteriores, obtienen otras relevantes:

- Se eluden aspectos básicos de la naturaleza de la Ciencia, ampliamente promulgados desde la Didáctica de las Ciencias.

- Apenas se hace referencia a cuestiones especialmente básicas en el aprendizaje de la Ciencia (p.e., favorecer el aprendizaje en equipo, que permita una construcción social del conocimiento, en analogía a como ocurre realmente en Ciencia).

- No se establece una relación clara y coherente entre las competencias, objetivos, contenidos y criterios de evaluación, relativos a la Ciencia escolar deseable para Primaria.
- La propuesta de contenidos es discontinua, en el sentido de que no promueve en la mayoría de los casos un desarrollo progresivo de los mismos a lo largo de la etapa.

No obstante, el hecho de que en el estado español las Comunidades Autónomas tengan competencias propias en Educación, hace tam bién necesario analizar las prescripciones particulares que estas plantean en su ámbito. Tra analizar el currículo estatal de Primaria, nuestro interés se centra en Andalucía; no solo por ser el contexto de los investigadores, sino tambié por los bajos niveles de competencia científica que vienen mostrando los escolares andaluce en las evaluaciones PISA, frente a los del resto de Comunidades. ${ }^{2}$ Ello incita a analizar las posibles causas que están detrás de esta situación y uno de los centros de atención es la propuesta oficial de Ciencia escolar para Primaria en Andalucía.

\section{Cuestión que se analiza}

Con lo expuesto, el problema de investigación que se plantea es: ¿Qué Ciencia escolar promueve el currículo oficial andaluz para la etapa de Primaria, y qué coherencia muestra con las sugerencias actuales en Didáctica de las Ciencias?

Para ello, se analiza la Orden de 10 de agosto de $2007^{3}$, donde se desarrolla el currícul correspondiente al área de Conocimiento del Medio (CM) para la Educación Primaria en Andalucía.

Las conclusiones de los estudios precedentes, antes citados, invitan a asumir la hipótesis de que dichas prescripciones presentan carencias respecto a la educación científica deseable para promover una adecuada alfabetizació científica desde la etapa de Primaria en Andalucía.

2 En la evaluación PISA 2009, Andalucía obtuvo 469 puntos en competencia científica, frente a los 488 puntos de media en España, sufriendo, incluso, un retroceso respecto a la evaluación PISA 2006. Más información en: http:/ / www.oei. es/divulgacioncientifica/opinionO079.htm.

3 Disponible en: http://www.juntadeandalucia.es/boja/2007/171/1

4 Parte de la bibliografía consultada para la determinación de estos estándares se cita a lo largo del artículo.
A fin de llevar a cabo el análisis, se utilizó un protocolo (ver Anexo) que ya ha sido validado por los autores en un estudio anterior (García-Carmona et al., 2014). El protocolo cons las siguientes dimensiones relacionadas la Ciencia escolar: epistemología y sociologia de la Ciencia; transposición didáctica de la Ciencia; axiología; aprendizaje de la Ciencia objetivos y competencias; contenidos; actividades; estrategias de enseñanza; recursos; y criteCade evaluación.

Cada una de las dimensiones incluye una serie de cuestiones junto a unos indicadores, a el análisis. Estos estándares surgen de quellos posicionamientos actuales con mayor consenso en el ámbito de la Didáctica de El analisis se concreta, pues, en valorar criticamente si el documento hace referencia al contenido de tales indicadores, y el modo en que lo hace.

Como decimos, el protocolo ya ha superado pruebas de validación; sin embargo, era necesario también someter el análisis a procesos de fiabilidad. Dado el carácter interpretativo del análisis, se combinaron estrategias de fiabilidad interjueces e intrajuez (Padilla, 2002). Para ello, dos de los autores realizaron inicialmente de manera independiente, un análisis completo del documento con ayuda del protocolo, puesta en común de los tados. El tercer investigador intervino en ta discrepancia por parte de los dos primeros. Asimismo, pocos meses después, uno de los investigadores volvió a realizar el mismo análisis, obteniendo así resultados aún más ricos que Son estos últimos resultados los que se muestran en este trabajo. 


\section{Resultados y discusión}

Se presentan, a continuación, los resultados del análisis para cada una de las dimensiones si bien, algunas de ellas aparecerán aglutinadas por su proximidad o relación, al objeto de facilitar su discusión.

\section{Epistemología y sociología de la Ciencia}

Existe amplio consenso en considerar la Naturaleza de la Ciencia (NDC) como componente básico de la alfabetización científica (Hodson, 2008). Actualmente no existe un posicionamiento unánime respecto a qué contenidos de NDC deben ser prioritarios en e currículo de Ciencia (García-Carmona et al., 2012). Sin embargo, algunos consensos se están imponiendo en los currículos escolares de Ciencia de muchos países (Vázquez y Manassero, 2012). Éstos ponen énfasis en el análisi reflexivo de aspectos epistemológicos (qué es la Ciencia, cómo se construye...) y sociológicos (interacciones entre científicos, papel de la mujer en la Ciencia, controversias sociocientíficas...) de la Ciencia.

El currículo andaluz, lo más que promueve son ciertas incursiones en cuestiones sociocientíficas; de modo que se echan en falta una part importante de aspectos básicos de la NDC, que bien pueden tratarse en Primaria con las adap taciones pertinentes (Akerson et al., 2011). Po ejemplo, distinguir el papel de las observaciones (descripciones, medidas y clasificaciones) las inferencias; la inducción y la provisionalidad del conocimiento; las dificultades a las que se enfrentan la Ciencia y los científicos en su desarrollo; etc. Reflexionar sobre estas cuestiones, desde edades tempranas, ayudará a evita la concepción habitualmente idealizada de la Ciencia entre la ciudadanía (García-Carmona et al., 2012).

Por otra parte, cabe decir que el documento plantea los contenidos desde una perspectiva problematizada, lo que insinúa un aprendizaje basado en la indagación. Sin embargo, que los alumnos aprendan investigando no conlleva que reflexionen y tomen conciencia del propio proceso de indagación (lo que estaría en el dominio de la NDC). Sería como creer que simplemente comiendo se aprende sobre la digestión.

Por tanto, la presencia de aspectos básicos de la NDC en la propuesta de contenidos y objetivos de aprendizaje debe ser explícita. Si no, como indican algunos estudios (e.g., Akerson y Abd-El-Khalick, 2003), seguirá sin ser considerada como contenido básico de la Ciencia escolar entre el profesorado.

\section{Transposición didáctica de la Ciencia}

La educación científica en Primaria requiere de diversos factores que, por un lado, hagan factible su implementación en la etapa, y, por otro, favorezcan el desarrollo competencial correspondiente en los escolares.

Es cierto que la Ciencia académica, y todas sus connotaciones socioculturales, deben ser el referente en la determinación de la alfabetización científica; sin embargo, su adaptación -o transposición didáctica- al ámbito educativo debe hacerse de acuerdo con las características psico-cognitivas de los escolares, y a los fines de la etapa educativa. Surge así la Ciencia escolar, cuyo fin no es únicamente proporcionar conocimientos escolares de (y sobre) Ciencia, sino también de una serie de actitudes y valores que ayuden a los escolares a ser mejores ciudadanos.

El proceso de transposición didáctica es también complejo, pero, al mismo tiempo, fundamental para diseñar la Ciencia escolar más adecuada a los intereses y experiencias de los escolares. Campbell y Lubben (2000), entre otros, consideran que la Ciencia escolar debe priorizar el análisis de fenómenos y situaciones palpables para los escolares en su entorno cotidiano. Así, ésta debe construirse partiendo del conocimiento y experiencias de los escolares sobre fenómenos naturales (y tecnológicos) que puedan observar, a fin de que estos evolucionen, paulatina y significativamente, hacia el conocimiento escolar deseable. El documento que nos ocupa hace una mención más o menos explícita a ello:

“(...) la propia experiencia de los distintos alum nos y alumnas (con las concepciones que manejan este respecto) constituye una información de especia relevancia." (p. 8).

Asimismo, establece posibles niveles de progresión para la construcción de los conocimientos a lo largo de la etapa, y con diferenciaciones para cada ciclo, partiendo desde planteamientos simples hasta otros más complejos. Se dice:

“(...) se puede partir de núcleos de problemas cercanos al alumnado, relativos al funcionamiento de lo más vivencial y relacionado con su propio. des

lo mas vivencial y relacionado con su propio entorno
a lo más general y estructural." (p. 11)

\section{Axiología}

Desde Primaria, la educación científica debe proveer al alumnado de actitudes básicas para afrontar el análisis de cuestiones sociocientíficas de controversia, con sentido crítico y responsable (Dolan et al., 2009). El documento hace referencia a ello, con especial atención a la consecución de un mundo más saludable y sostenible:

"La toma de conciencia sobre temas y problemas que afectan a todas las personas en un mundo globalizado, entre los que se considerarán la salud. la pobreza en el mundo, el agotamiento de los recurso naturales, la superpoblación la contaminación calentamiento de la Tierra (....).'(p. 5)

Creemos, pues, que favorece que tales problemáticas sean concebidas como un contenido esencial de la educación científica. No en vano el profesorado suele ser bastante reacio a incluirlas en clase frente a otros contenidos más clásicos (Lee y Witz, 2009).

Por otra parte, cabe destacar que el documento andaluz omite otra cuestión especialmente importante: discernir lo que es científico de lo que no lo es (pseudociencia), a tenor del bombardeo continuo de publicidad con men- sajes "científicos" (Campanario et al., 2001). Promover el análisis de esto nos parece de vital importancia para una adecuada alfabetización científica; sobre todo, cuando proliferan las "dietas milagro", en momentos en los que la obesidad supone un problema cada vez más grave entre la población infantil y adolescente. $\mathrm{O}$ bien, la atención que suelen prestar los jóvenes a la astrología como una "verdad científica" e infalible, por poner algunos ejemplos.

\section{Aprendizaje de la Ciencia}

El aprendizaje de la Ciencia tiene una serie de peculiaridades que lo diferencian del aprendizaje de otras disciplinas (Pozo y Gómez 1998). Muchas de las ideas intuitivas sobre los fenómenos naturales se desarrollan a edades muy tempranas, por lo general, antes de que se inicie la educación científica (Rodríguez y Aparicio, 2004); de modo que suelen estar fuertemente arraigadas en los escolares. Por esta razón, aunque se establezcan estrategias de enseñanza orientadas a provocar el cambio conceptual, no siempre se logra el objetivo. El documento analizado habla de que:

“... son numerosos los recursos y actividades que pueden resultar de interés en el tratamiento de los problemas propuestos, sin olvidar que la propia ex periencia de los distintos alumnos y alumnas (con las concepciones que manejan a este respecto) constituy una información de especial relevancia" (p. 8).

A parte de esto, todo lo referido al aprendizaje se recoge en las disposiciones generales del documento, a modo de orientaciones genéricas e idénticas para todas las áreas, y donde solo hace parca alusión a la necesidad de "afianzar la motivación del alumnado" para lograr los objetivos de la etapa. Creemos que esto favorece poco a que luego cale en las aulas andaluzas de Primaria otros enfoques de enseñanza más propicios para lograr un aprendizaje significativo de la Ciencia (véase el contenido de la dimensión 4 en el Anexo).

Por otra parte, el documento sí hace mención a la importancia de la interacción comunicativa 
en el aprendizaje. Con carácter general, menciona que los centros "arbitrarán métodos que tengan en cuenta los diferentes ritmos de aprendizaje del alumnado, favorezcan la capacidad de aprender por sí mismo y promuevan el trabajo en equipo." (p. 5). Poco después, dice también que "La metodología didáctica en esta etapa educativa será fundamentalmente activa y participativa favoreciendo el trabajo individual y cooperativo del alumnado en el aula (...)". Por tanto, puede decirse que sintoniza con un enfoque de aprendizaje socio-constructivista, uno de los más pertinentes para aprender Ciencia (Ametller, 2011).

Asimismo, menciona la idoneidad del área de CM para promover el desarrollo de habilidades socio-afectivas en los escolares:

"El tratamiento educativo de problemas relativos a la salud y al bienestar puede adoptar perspectivas formulaciones muy variadas, abarcando ámbitos tan diversos como el conocimiento del propio cuerpo, la educación afectiva y sexual o la participación pública como ciudadano." (p. 11).

Hace referencia también al papel que desempeñan la curiosidad e intereses de los escolares en el aprendizaje de la Ciencia:

"Desde el área de CM se ofrece la posibilidad de organizar el curriculo en torno a una serie de grandes problemáticas o núcleos temáticos que (...) tienen posibilidades de conectar con los conocimientos e intereses del alumnado (...)" (p. 7).

$\mathrm{Y}$, desde las prescripciones generales para la etapa, se alude a la importancia de que los aprendizajes sean útiles y funcionales:

"La aplicación de lo aprendido a las situaciones de la vida cotidiana, favoreciendo las actividades que capaciten para el conocimiento y análisis del medio que nos circunda (...)" (p. 4).

Sin embargo, el documento andaluz no hace referencia explícita a la importancia de un buen clima de aula, que promueva un ambien te agradable de participación, comunicación convivencia. Quizás esto puede resultar muy genérico y válido para cualquier área; pero tiene especial relevancia en el ámbito de la educación científica, donde el papel de las emociones y la afectividad de los escolares está siendo objeto de numeroso estudios (Garritz, 2009), entre otras razones, por el descenso alarmante del interés de los escolares por la Ciencia en los últimos años (Rocard et al., 2007; COSCE, 2011).

\section{Objetivos y competencias}

Sobre los objetivos para el área de CM, el documento se refiere a los establecidos en el currículo estatal y no hace formulación propia. Lo más que hace, en la presentación de las enseñanzas mínimas, es proponer "características peculiares que impregnan todas sus áreas o ámbitos", que vienen a ser como los objetivos generales para la etapa en Andalucía.

Sí hace alusión explícita a que deben ser los equipos de profesorado quienes concreten en sus programaciones didácticas los objetivos más específicos (por tanto, flexibles y adaptables) según las necesidades e intereses de su alumnado.

Por otra parte, el documento apenas dedica atención a las competencias. Prácticamente se remite al currículo estatal, y luego hace una brevísima y genérica presentación de cada una de ellas en las prescripciones generales. En la descripción del área no se mencionan las competencias, por lo que menos aún se orienta sobre cómo se puede contribuir desde el área a su desarrollo.

Por tanto, si el documento delega en el currículo estatal todo lo relativo a los objetivos y competencias para el área de CM, traslada al ámbito andaluz todas sus deficiencias sobre ello (García-Carmona et al., 2014), que pueden resumirse en que: (I) se ofrecen orientaciones sobre la contribución del área a las distintas competencias básicas, pero no se establece una relación clara de éstas con los objetivos del área; y (II) se plantean, por un lado, los objetivos y, por otro, las competencias, de modo que no se aclara cuáles son realmente las metas educativas, o de mayor rango, si los objetivos, las competencias o ambos. Montero (2008) ha manifestado también la necesidad de hacer más explícita la vinculación entre objetivos y competencias en el currículo oficial.

\section{Contenidos}

Respecto a los contenidos, el currículo andaluz propone para el área de $\mathrm{CM}$ ocho núcleos temáticos con un enfoque interdisciplinar globalizado. Los núcleos son: 1 . La construcción histórica, social y cultural de Andalucía; 2 Paisajes andaluces; 3. El patrimonio en Andalucía; 4. Igualdad, convivencia e interculturalidad 5. Salud y bienestar; 6. Progreso tecnológico y modelos de desarrollo; 7. El uso responsable de los recursos; y 8. La incidencia de la actividad humana en el medio. El documento sugiere relaciones entre estos y los establecidos en el currículo estatal. Asimismo, para cada núcleo plantea problemáticas generales que orientarían el desarrollo progresivo de los contenidos en cada ciclo.

El área integra conocimientos procedentes de las ciencias experimentales y de las ciencias sociales, de modo que un enfoque globalizado de los contenidos es comprensible. Sin embargo, la perspectiva predominantemente social de las problemáticas menoscaba una parte considerable de la Ciencia escolar deseable para Primaria. Nos preguntamos, ¿por que promueve un enfoque donde la (escasa) ciencia experimental que sugiere debe estar plenamente "socializada" $y$, en cambio, la ciencia social propuesta no integra aspectos relacionado con la educación científica? Por ejemplo, en el núcleo temático el "Progreso tecnológico y los modelos de desarrollo", se proponen cuestione tanto relativas a tipos de máquinas como a la desigualdades en el mundo a causa del desarrollo científico-tecnológico. Pero cuando plantea el núcleo temático "Igualdad, convivencia e interculturalidad", ¿por qué no hace ningun sugerencia, por ejemplo, al papel de la mujer en la Ciencia y su infravaloración histórica en este campo? Esta cuestión, fundamental para promover una adecuada alfabetización científica, bien podía integrarse explícitamente en ese bloque, en principio, de ciencia social.
Ya hemos defendido la importancia de integrar problemáticas sociocientíficas en la alfabetización científica básica; sin embargo, ésta no puede estar basada casi exclusivamente en ello. También deben promoverse conocimientos conceptuales (conceptos, datos, principios, teorías...) y procedimentales (experimentación, modelización...) (Dillon, 2009), que permitan a los escolares interpretar y predecir fenómenos más concretos (no tan globales o macrodimensionales) de su entorno más inmediato. Esto implicaría, desde una visión problematizada, promover igualmente la indagación de cuestiones como: ¿por qué en verano los días son más largos que en invierno?, ¿cómo se genera la electricidad que consumimos en casa?, ¿por qué flota un balón y no una canica?... Con el planteamiento actual del documento andaluz esto resulta parcamente sugerido. Del total de problemáticas propuestas, solo alrededor del $4 \%$ podrían considerarse específicas de Ciencia escolar y sin un cariz predominantemente sociocientífico.

\section{Estrategias, actividades y recursos de} enseñanza

Más allá de las críticas comentadas respecto los contenidos, creemos que su estructuración problematizada es un acierto. Como hemos dicho, sugiere un enfoque del aprendizaje basado en la indagación; hoy día considerado de los más idóneos para la educación científica (Harlen, 2013). Sin embargo, el documento apenas sugiere cómo promoverlo en el aula. Solo alude a que la selección, formulación y tratamiento de los problemas se establezca de forma progresiva, y que éstos se refieran a situaciones que resulten familiares a los escolares. También, en alguna ocasión sugiere la realización de actividades experimentales y la promoción de algún debate en clase.

Pensamos que si se apuesta por un enfoque problematizado de los contenidos, ade- 
más como algo claramente diferenciado de las prescripciones del currículo estatal, debería ofrecer algunas orientaciones didácticas y me todológicas que favorezcan su implementación en el aula. De lo contrario, esas problemática sugeridas en el documento andaluz posiblemente terminen siendo asumidas por el profesorado, y diseñadores de materiales didácticos, como simples enunciados de los contenidos, sin otra trascendencia. De hecho, estudios recientes revelan la escasa incidencia del modelo de aprendizaje por investigación entre el profesorado de Primaria en Andalucía (Cañal et al., 2011).

Por otra parte, cabe resaltar la promoción del documento sobre el uso de una variedad de recursos para la enseñanza sobre el medio, tale como el uso de las TIC, el entorno cotidiano d los escolares, la visita a museos y exposiciones de ciencia, espacios naturales, la prensa, etc.

\subsection{Criterios de evaluación}

Para valorar el grado de consecución de los aprendizajes, y ligado a la propuesta de contenidos, el documento incluye un apartado denominado "criterios de valoración de los proceso de aprendizaje"; sin embargo, estos son excesivamente genéricos. Por ejemplo, en el caso de núcleo "Progreso tecnológico y modelos de desarrollo", se dice:

"Aunque las metas educativas relacionadas con estos problemas son complejas y solo se pueden conseguir a largo plazo, durante la etapa de educación primaria el alumnado puede ir progresando desde aprendizajes más centrados en la descripción y analisis de aspectos diversos (...) hasta analisis mas conplejos (...)." (p. 12)

Entendemos que, junto a los objetivos y grados de desarrollo competencial, los criterios de evaluación son los que determinan qué niveles de aprendizaje se esperan de los escolares. Con la formulación anterior en poco se contribuye a ello, ya que son orientaciones excesivamente abiertas, que bien pueden servir igualmente para un nivel de ESO o de Bachillerato.

\section{Conclusiones}

El análisis del estado actual de la educación científica básica en Andalucía no debe limitarse a los materiales didácticos que se diseñan, y a la práctica docente en las aulas (ambas cuestiones, actualmente en investigación por los autores); debe ocuparse también del currículo oficial del que ha de emanar lo anterior.

Seguramente no haya que asumir un currículo oficial como un tratado didáctico y metodológico totalmente elaborado para su desarrollo en las aulas (Gimeno, 2002); de hecho, el documento analizado regula que serán los centros y equipos docentes quienes lo deben concretar. Sin embargo, éste se ocupa de hacer recomendaciones respecto a los objetivos, competencias, contenidos, metodología y criterios de evaluación para la educación científica en Primaria. Entonces, ¿hasta dónde deben llegar esas recomendaciones "oficiales"? Dejando de lado debates de política educativa, creemos que los currículos oficiales de Ciencia escolar deben ser, en cualquier caso, consonantes con las últimas tendencias en Didáctica de la Ciencia, y, sobre todo, hacer las mejores recomendaciones para alfabetizar científicamente a los escolares. Indudablemente, la inclusión de tales recomendaciones no garantiza que sean asumidas por el profesorado en su práctica; pero si no se recogen en estos documentos marcos, muy posiblemente no se consideren esenciales $y$, por tanto, tengan poca incidencia en las aulas.

El análisis revela que la educación científica promovida oficialmente para Primaria en Andalucía, incluye partes concordantes con las actuales tendencias en Didáctica de la Ciencia. Sin embargo, también tiene omisiones, alusiones excesivamente superficiales, o poco clarificadoras, que, creemos, no favorecen la educación científica deseable para la etapa. En consecuencia, y para reformas educativas venideras, recomendaríamos lo siguiente:

Promover explícitamente una visión adecuada de la Ciencia con reflexiones que incidan en: los objetivos y finalidades de la Ciencia, su base empírica, las características y procedimientos habituales en su construcción; la Ciencia como componente cultural; la construcción del conocimiento científico como fruto de colaboraciones y consensos; la importancia de pensamiento divergente en el desarrollo de la Ciencia; el papel de la creatividad en la construcción de conocimiento científico; el carácter evolutivo de la Ciencia; y los conflictos éticos y morales que surgen en torno al desarrollo científico.

Fomentar que los escolares sean capaces de diferenciar la pseudociencia de lo científico en mensajes informativos y publicitarios, como parte básica de su formación integral como ciudadano. Esto puede verse favorecido si se auspicia un primer conocimiento de los aspecto señalados anteriormente.

Hacer explícita la importancia de la afectividad en la educación científica. Además de promover el trabajo en equipo, el aprendizaje cooperativo, y la atención a distintos ritmos de aprendizaje, insistir en el diseño de tareas que ofrezcan a los escolares la oportunidad de ser exitosos, mediante retos en ambientes sanos y confortables, y que propugnen el reconocimiento, el esfuerzo, el progreso y la automejora continua (Garritz, 2009).

Sobre los elementos curriculares, proponer objetivos claros y factibles para una alfabetización científica inicial; orientaciones sobre cómo contribuir al desarrollo de las competencias básicas; relaciones coherentes y explícitas entre los objetivos y las competencias básicas; una propuesta más equilibrada de contenidos de ciencias experimentales y de ciencias sociales, a la vez que coherente con un enfoque integrador de estos; mayor atención a contenidos conceptuales y procedimentales, que incidan en el análisis de fenómenos concreto (no macrodimensionales); criterios de evaluación no excesivamente genéricos y claramente relacionados con los objetivos y competencias previstos.

Dada la estructura problematizada de los contenidos, hacer recomendaciones didácticas y metodológicas para el aprendizaje de la Ciencia basado en la investigación escolar.

\section{REFERENCIAS}

Akerson, V.L., Buck, G.A., Donnelly, L.A., Nargund, V., Weiland, I.S. (2011). The importance of teaching and learning nature of science in the early childhood years. Journal of Science Education and Technology, 20, 537-549.

Akerson, V.L. y Abd-El-Khalick, F. (2003). Teaching elements of nature of science: a yearlong case study of a fourth-grade teacher. Journal of Research in Science Teaching, 40(10), 10251049.

Ametller, J. (2011). La enseñanza dialogada en la construcción del conocimiento físico y químico. En A. Caamaño (Coord.), Didáctica de la Física y la Química (pp. 105-120). Barcelona: Graó.

Banet, E. (2010). El medio natural en la LOE ¿continuidad o cambio en el currículo de educación primaria? Investigación en la Escuela 70, 71-78.

Campanario, J. M., Moya, A. y Otero, J. C. (2001). Invocaciones y usos inadecuados de la Ciencia en la publicidad. Enseñanza de las Ciencias, 19(1), 45-56.

Campbell, B. y Lubben, F. (2000). Learning science through contexts: helping pupils make sense of everyday situation. International Journal of Science Education, 22(3), 239-252.

Cañal, P., Travé, G. y Pozuelos, F.J. (2011). Análisis de obstáculos y dificultades de profesores y estudiantes en la utilización de enfoques de investigación escolar. Investigación en la Escuela, 73, 5-26.

COSCE (Confederación de Sociedades Científicas de España) (2011). Informe Enciende (Enseñanza de las Ciencias en la Didáctica escolar para edades tempranas en España). Madrid: COSCE.

De Pro, A. y Miralles, P. (2009). El currículo de Conocimiento del Medio Natural, Social y Cultural en la Educación Primaria. Educatio Siglo XXI, 27(1), 59-96.

Dillon, J. (2009). On scientific literacy and curriculum reform. International Journal of Environmental \& Science Education, 4(3), 201-213.

Dolan, T.J., Nichols, B.H. y Zeidler, D.L. (2009). Using Socioscientific Issues in Primary Classrooms. Journal of Elementary Science Education, 21(3), 1-12. 
Eurydice (2011). Science Education in Europe: National Policies, Practices and Research. Recuperado octubre 26, 2013 de: http://eacea. ec.europa.eu/education/eurydice

García, S., Domínguez, J.M. y García-Rodeja, E. (2002). Razonamiento y argumentación en ciencias. Diferentes puntos de vista en el currículo oficial. Enseñanza de las Ciencias, 20(2), 217-228.

García-Carmona, A., Criado, A.M. y Cañal, P. (2014). ¿Qué educación científica se promueve para la etapa de Primaria en España? Un análisis de las prescripciones oficiales de la LOE. Enseñanza de las Ciencias, 32(1), 139-157.

García-Carmona, A., Vázquez, A. y Manassero, M.A. (2012). Comprensión de los estudiante sobre naturaleza de la ciencia: análisis del estado actual de la cuestión y perspectivas. Enseñanza de las Ciencias, 30(1), 23-34.

Garritz, A. (2009). La afectividad en la enseñanz de las ciencias. Educación Química, no extra 212-219.

Gimeno, J. (2002). El curriculum: una reflexión sobre la práctica. Madrid: Morata.

Harlen, W. (2013). Assessment \& Inquiry-Based Science Education: Issues in Policy and Practice. Trieste: Global Network of Science Academies.

Hodson, D. (2008). Towards Scientific Literacy. Rotterdam: Sense Publishers.
Lee, H. y Witz, K.G. (2009). Science Teachers' Inspiration for Teaching Socio-scientific Issues: Disconnection with reform efforts. International Journal of Science Education, 31(7), 931-960. Montero, A. (2008). Competencias educativas y objetivos como capacidades. Escuela Española, 3783, 35 .

Osborne, J. y Dillon, J. (Coord.) (2008). Science Education in Europe: Critical Reflections. London: Nuffield Foundation.

Padilla, M.T. (2002). Técnicas e Instrumentos para el Diagnóstico y la Evaluación Educativa. Madrid: CCS.

Pozo, J.I. y Gómez, M.A. (1998). Aprender y ensenar Ciencia. Madrid: Morata.

Rocard, M., Csermely, P., Jorde, D., Lenzen, D., Walberg, H. y Hemmo, V. (2007). Science Education Now: A Renewed Pedagogy for the Future of Europe. Brussels: Directorate General for Research, Science, Economy and Society.

Rodríguez, M. y Aparicio, J.J. (2004). Los estudios sobre el cambio conceptual y la enseñanza de las ciencias. Educación Química, 15(3), 270-280.

Vázquez, A. y Manassero, M.A. (2012). La selección de contenidos para enseñar naturaleza de la ciencia y tecnología (parte 1): Una revisión de las aportaciones de la investigación didáctica. Revista Eureka sobre Enseñanza y Divulgación de las Ciencias, 9(1), 2-31.
ANEXO

Protocolo aplicado en el análisis del currículo oficial del área de Conocimiento del Medio (Natural y Tecnológico) para Andalucía

\begin{tabular}{|c|c|c|}
\hline Categorías & $\begin{array}{c}\text { CUESTIONES } \\
\text { PARA EL } \\
\text { ANÁLISIS DEL } \\
\text { CURRÍCULO }\end{array}$ & $\begin{array}{l}\text { - OPCIONES VÁlIDAS SEGÚN EL PARADIGMA } \\
\text { DIDÁCTICO ACTUAL (ESTÁNDARES) }\end{array}$ \\
\hline \multirow[t]{2}{*}{$\begin{array}{l}\text { 1. Epistemología } \\
\text { y sociología de } \\
\text { la Ciencia }\end{array}$} & $\begin{array}{l}1.1 . \text { ¿Cómo se } \\
\text { caracteriza el } \\
\text { conocimiento } \\
\text { científico? }\end{array}$ & $\begin{array}{l}\text { - Es útil para interpretar y comprender el medio físico (natural } \\
\text { y tecnológico), así como para hacer predicciones sobre los } \\
\text { fenómenos que en él ocurren (que explica y predice) } \\
\text { - Tiene carácter provisional y evolutivo } \\
\text { - Forma parte de la cultura actual } \\
\text { - Se establece por consenso: la "objetividad" del conocimiento } \\
\text { científico surge a partir de acuerdos de la comunidad cientí- } \\
\text { fica, por tanto, está basado en una intersubjetividad } \\
\text { - Es una actividad generalmente colectiva, desarrollada en } \\
\text { equipos de trabajo } \\
\text { - Al referirse a la realidad (y construido en el contexto de las } \\
\text { ciencias naturales o factuales), se basa en pruebas empíricas } \\
\text { - Emplea argumentos racionales } \\
\text { - La decisión sobre su aplicación no es neutral, y puede entrar } \\
\text { en conflicto con valores éticos y morales de determinados } \\
\text { grupos sociales } \\
\text { - En su desarrollo juegan un papel importante la imaginación, } \\
\text { la creatividad y la inspiración } \\
\text { - Suele tener carácter multidisciplinar } \\
\text { - Es legítimo que se hagan diferentes interpretaciones de los } \\
\text { mismos datos y que, por tanto, existan discrepancias (pensa- } \\
\text { miento divergente) } \\
\text { - Sus ámbitos de desarrollo están condicionados por intereses } \\
\text { socioculturales, medioambientales..., a la vez que el desarro- } \\
\text { llo científico condiciona estilos de vida, desarrollo sociona- } \\
\text { tural y cultural... }\end{array}$ \\
\hline & $\begin{array}{l}\text { 1.2. ¿Cómo } \\
\text { se concibe la } \\
\text { investigación } \\
\text { científica? }\end{array}$ & $\begin{array}{l}\text { - Es una actividad orientada a abordar problemas no resueltos } \\
\text { en relación con el medio físico } \\
\text { - No hay una sola manera de investigar, por lo que no existe un } \\
\text { único método científico ni, por tanto, universal } \\
\text { - Es un continuo proceso cíclico de hacer preguntas y buscar } \\
\text { respuestas que originan nuevas preguntas, en relación con la } \\
\text { naturaleza y sus fenómenos } \\
\text { - Requiere el establecimiento de hipótesis cuya validez debe } \\
\text { ser comprobada } \\
\text { - Implica tener destrezas en el análisis e interpretación de da- } \\
\text { tos }\end{array}$ \\
\hline
\end{tabular}




\begin{tabular}{|c|c|c|}
\hline $\begin{array}{l}\text { 2. Transposición } \\
\text { didáctica de la } \\
\text { Ciencia }\end{array}$ & $\begin{array}{l}\text { 2.1. ¿Qué relación } \\
\text { se establece entre } \\
\text { el conocimiento } \\
\text { científico, el } \\
\text { cotidiano y el } \\
\text { escolar sobre el } \\
\text { medio? }\end{array}$ & $\begin{array}{l}\text { - En etapas educativas básicas es aconsejable dar prioridad al } \\
\text { estudio de fenómenos y situaciones fácilmente observables } \\
\text { por los escolares en su entorno cotidiano } \\
\text { - La ciencia escolar debe venir dada por un proceso de integra- } \\
\text { ción y adaptación de la ciencia académica al contexto y las } \\
\text { características psico-cognitivas de los escolares } \\
\text { - La ciencia escolar se construye partiendo del conocimiento } \\
\text { y experiencias cotidianos de los escolares, sobre el porqué de } \\
\text { los fenómenos naturales (y artificiales) observables, a fin de } \\
\text { que éste evolucione, paulatina y significativamente, hacia el } \\
\text { conocimiento escolar considerado adecuado }\end{array}$ \\
\hline 3. Axiología & $\begin{array}{l}\text { 3.1. ¿Qué } \\
\text { actitudes y } \\
\text { valores (éticos } \\
\text { y morales) se } \\
\text { promueven en } \\
\text { relación con } \\
\text { la ciencia y su } \\
\text { desarrollo? }\end{array}$ & $\begin{array}{l}\text { Desarrollo de valores, actitudes y comportamientos que ayu- } \\
\text { den a conseguir un entorno socio-natural saludable y soste- } \\
\text { nible } \\
\text { - Desarrollo de un pensamiento crítico y responsable ante el } \\
\text { análisis satisfactorio de situaciones sociocientíficas (aplica- } \\
\text { ción del principio de precaución), y de distinguir Ciencia de } \\
\text { pseudociencia }\end{array}$ \\
\hline \multirow[t]{3}{*}{$\begin{array}{l}\text { 4. Aprendizaje } \\
\text { de la Ciencia }\end{array}$} & $\begin{array}{l}4.1 . \text { ¿Qué es } \\
\text { aprender y qué } \\
\text { influye en el } \\
\text { aprendizaje } \\
\text { escolar? }\end{array}$ & $\begin{array}{l}\text { - Aprender significa adquirir conocimientos y habilidades me- } \\
\text { diante procesos mentales de construcción y reconstrucción } \\
\text { permanentes. } \\
\text { - Influyen la motivación, el desarrollo intelectivo, la memo- } \\
\text { ria, los conocimientos previos, las actividades y estrategias } \\
\text { de enseñanza, así como la utilidad y frecuencia de uso de lo } \\
\text { aprendido }\end{array}$ \\
\hline & $\begin{array}{l}\text { 4.2. ¿Qué debe } \\
\text { hacer el alumno } \\
\text { para aprender } \\
\text { Ciencia? }\end{array}$ & $\begin{array}{l}\text { - Movilizar sus conocimientos iniciales para tratar de com- } \\
\text { prender lo nuevo } \\
\text { - Tomar conciencia de las potencialidades y carencias propias, } \\
\text { así como tener voluntad, responsabilidad y perseverancia } \\
\text { para adquirir nuevos aprendizajes }\end{array}$ \\
\hline & $\begin{array}{l}\text { 4.3. ¿Qué función } \\
\text { y relevancia } \\
\text { tienen los } \\
\text { conocimientos } \\
\text { previos del } \\
\text { alumno en el } \\
\text { aprendizaje? }\end{array}$ & $\begin{array}{l}\text { - Punto de partida en todo proceso de aprendizaje } \\
\text { - Deben orientar la adquisición de los nuevos aprendizajes me- } \\
\text { diante actividades metacognitivas, que ayuden a los escolares } \\
\text { a tomar conciencia de las limitaciones de sus conocimientos } \\
\text { previos y de cómo otros conocimientos (los científicos) pue- } \\
\text { den ser más válidos o efectivos }\end{array}$ \\
\hline
\end{tabular}

\begin{tabular}{|c|c|c|}
\hline & $\begin{array}{l}\text { 4.4. ¿Qué } \\
\text { importancia y } \\
\text { función tiene } \\
\text { la interacción } \\
\text { comunicativa } \\
\text { entre los alumnos } \\
\text { en el aprendizaje? }\end{array}$ & $\begin{array}{l}\text { - Construcción de aprendizajes en un plano de similitud cog- } \\
\text { nitiva (Dialéctica entre iguales que desplaza la "autoridad" } \\
\text { del profesor como criterio de "lo que hay que aprender" hacia } \\
\text { "las conclusiones a las que hemos llegado, entre todos, con la } \\
\text { ayuda del profesor", después de "ver" y analizar las posibles } \\
\text { explicaciones) } \\
\text { - Favorecer el aprendizaje cooperativo, que ayude especial- } \\
\text { mente a los estudiantes que tienen más dificultades y enri- } \\
\text { quezca a los más aventajados } \\
\text { - Promover el aprendizaje colaborativo, donde cada alumno } \\
\text { hace su mejor aportación en aras de lograr el mejor apren- } \\
\text { dizaje común }\end{array}$ \\
\hline & $\begin{array}{l}\text { 4.5. ¿Qué tipo } \\
\text { de clima de aula } \\
\text { y de motivación } \\
\text { es conveniente } \\
\text { promover? }\end{array}$ & $\begin{array}{l}\text { - El que propicie que los estudiantes desarrollen su creatividad, } \\
\text { adquieran confianza y asuman un nivel adecuado de autono- } \\
\text { mía, iniciativa y responsabilidad, dentro de un clima afectivo }\end{array}$ \\
\hline & $\begin{array}{l}\text { 4.6. ¿Cuál es el } \\
\text { papel que se da } \\
\text { a la curiosidad } \\
\text { y a los intereses } \\
\text { personales de } \\
\text { los alumnos en } \\
\text { el aprendizaje } \\
\text { escolar sobre el } \\
\text { medio? }\end{array}$ & $\begin{array}{l}\text { - Papel fundamental que se puede aprovechar para partir de } \\
\text { los problemas específicos que interesan a los escolares y de } \\
\text { ahí lograr que aborden los problemas generales que promue- } \\
\text { ve el currículo. }\end{array}$ \\
\hline \multirow[t]{3}{*}{$\begin{array}{l}\text { 5. Objetivos y } \\
\text { competencias }\end{array}$} & $\begin{array}{l}\text { 5.1. ¿Cómo se } \\
\text { formulan los } \\
\text { objetivos de la } \\
\text { enseñanza sobre } \\
\text { el medio? }\end{array}$ & - Como una orientación flexible y adaptable a cada escolar \\
\hline & $\begin{array}{l}\text { 5.2. ¿Cuáles } \\
\text { se consideran } \\
\text { los objetivos } \\
\text { prioritarios de } \\
\text { la enseñanza } \\
\text { sobre el medio en } \\
\text { Primaria? }\end{array}$ & $\begin{array}{l}\text { - Deben considerarse prioritarios aquellos que favorezcan el } \\
\text { desarrollo de una alfabetización científica básica (o compe- } \\
\text { tencia en el conocimiento y la interacción con el mundo fí- } \\
\text { sico), mediante: } \\
\text { - a) La adquisición de conocimientos científico-tecnológicos } \\
\text { básicos } \\
\text { - b) El desarrollo de habilidades y destrezas afines a la activi- } \\
\text { dad científica } \\
\text { - c) Una comprensión básica de algunos elementos de la } \\
\text { naturaleza de la ciencia }\end{array}$ \\
\hline & $\begin{array}{l}\text { 5.3. ¿Cómo se } \\
\text { promueve el } \\
\text { desarrollo de las } \\
\text { competencias } \\
\text { relativas al } \\
\text { conocimiento del } \\
\text { medio? }\end{array}$ & $\begin{array}{l}\text { - A través de un planteamiento coherente entre los objetivos, } \\
\text { contenidos, actividades, metodologías de enseñanza/apren- } \\
\text { dizaje, y sistema de evaluación (proceso, instrumentos y } \\
\text { criterios de evaluación), que favorezcan el desarrollo de los } \\
\text { elementos competenciales anteriores }\end{array}$ \\
\hline
\end{tabular}




\begin{tabular}{|c|c|c|}
\hline & $\begin{array}{l}\text { 5.4. ¿Al } \\
\text { desarrollo de qué } \\
\text { competencias } \\
\text { básicas } \\
\text { contribuye el área } \\
\text { de conocimiento } \\
\text { del medio } \\
\text { (además de a } \\
\text { la competencia } \\
\text { científica)? }\end{array}$ & $\begin{array}{l}\text { - Competencia matemática } \\
\text { - Competencia social y ciudadana } \\
\text { - Competencia cultural y artística } \\
\text { - Competencia para aprender a aprender } \\
\text { - Competencia en comunicación lingǘstica } \\
\text { - Competencia en el tratamiento de la información y compe- } \\
\text { tencia digital } \\
\text { - Autonomía e iniciativa personal }\end{array}$ \\
\hline \multirow[t]{4}{*}{ 6. Contenidos } & $\begin{array}{l}\text { 6.1. ¿Cómo se } \\
\text { conciben los } \\
\text { contenidos y su } \\
\text { función en el } \\
\text { aprendizaje sobre } \\
\text { el medio? }\end{array}$ & $\begin{array}{l}\text { - Como medios o escenarios para que los escolares aprendan } \\
\text { lo que se especifica en los objetivos y desarrollen las compe- } \\
\text { tencias básicas previstas }\end{array}$ \\
\hline & $\begin{array}{l}\text { 6.2. ¿Qué tipos } \\
\text { de contenidos } \\
\text { sobre el medio } \\
\text { se consideran } \\
\text { relevantes? }\end{array}$ & $\begin{array}{l}\text { - Conocimientos (conceptuales, procedimentales y actitudi- } \\
\text { nales) relacionados y no fragmentados, que sean útiles en la } \\
\text { vida cotidiana y útiles para responder a las preguntas de los } \\
\text { escolares }\end{array}$ \\
\hline & $\begin{array}{l}\text { 6.3. ¿Qué fuentes } \\
\text { de contenidos } \\
\text { relativos al medio } \\
\text { son necesarias } \\
\text { o convenientes } \\
\text { utilizar? }\end{array}$ & $\begin{array}{l}\text { - La realidad socionatural, libros de divulgación, los medios de } \\
\text { comunicación (TV, prensa, Internet...),... }\end{array}$ \\
\hline & $\begin{array}{l}\text { 6.4. ¿Cómo } \\
\text { organizar y } \\
\text { secuenciar los } \\
\text { contenidos? }\end{array}$ & $\begin{array}{l}\text { - Mediante un hilo conductor que tenga en cuenta la lógica } \\
\text { psicológica del escolar, a la vez que cierta coherencia con la } \\
\text { epistemología del conocimiento científico (secuenciación } \\
\text { progresiva) }\end{array}$ \\
\hline 7. Actividades & $\begin{array}{l}\text { 7.1. ¿Qué tipos } \\
\text { de actividades } \\
\text { y tareas es } \\
\text { necesario realizar } \\
\text { para promover } \\
\text { los aprendizajes } \\
\text { perseguidos en el } \\
\text { conocimiento del } \\
\text { medio? }\end{array}$ & $\begin{array}{l}\text { - Por ejemplo: } \\
\text { - Actividades de motivación y de diagnóstico del conocimien- } \\
\text { to inicial de los escolares } \\
\text { - Actividades de construcción de los aprendizajes } \\
\text { - Actividades de síntesis y de evaluación }\end{array}$ \\
\hline $\begin{array}{l}\text { 8. Estrategias de } \\
\text { enseñanza }\end{array}$ & $\begin{array}{l}8.1 . \text { ¿Cómo se } \\
\text { promueve la } \\
\text { significatividad y } \\
\text { la funcionalidad } \\
\text { en la enseñanza y } \\
\text { aprendizaje sobre } \\
\text { el medio? }\end{array}$ & $\begin{array}{l}\text { - Mediante estrategias de selección de problemas a investigar } \\
\text {-referidos a la realidad socionatural y cotidiana de los esco- } \\
\text { lares-; de planificación de lo que se va a realizar para abordar } \\
\text { los problemas; ejercicios metacognitivos; recopilación e in- } \\
\text { terpretación de datos; extracción de conclusiones; comuni- } \\
\text { cación de resultados; etc. }\end{array}$ \\
\hline
\end{tabular}

\begin{tabular}{|l|l|l|}
\hline & $\begin{array}{l}\text { 8.2. ¿Qué } \\
\text { esquema lógico } \\
\text { de secuenciación } \\
\text { de actividades se } \\
\text { promueve o se } \\
\text { emplea? }\end{array}$ & $\begin{array}{l}\text { - Lógica que tenga en cuenta las preguntas y el desarrollo } \\
\text { psico-cognitivo de los escolares, que favorezcan el desarrollo } \\
\text { de investigaciones escolares en consonancia con lo descrito } \\
\text { antes }\end{array}$ \\
\hline 9. Recursos & $\begin{array}{l}\text { 9.1. ¿Qué } \\
\text { recursos y } \\
\text { materiales } \\
\text { curriculares se } \\
\text { consideran más } \\
\text { importantes en la } \\
\text { ensenanza de la } \\
\text { ciencia? }\end{array}$ & $\begin{array}{l}\text { - Aquellos que permitan a los escolares construir aprendizajes } \\
\text { útiles y funcionales relativos a su entorno más cercano y coti- } \\
\text { diano (programas de actividades, uso de las TIC, objetos del } \\
\text { entorno cotidiano, exposiciones y ferias de ciencia,...) }\end{array}$ \\
\hline $\begin{array}{l}\text { 10. Criterios de } \\
\text { evaluación }\end{array}$ & $\begin{array}{l}\text { 10.1. ¿Qué } \\
\text { criterios de } \\
\text { evaluación se } \\
\text { deben promover } \\
\text { en el aprendizaje } \\
\text { de la ciencia? }\end{array}$ & $\begin{array}{l}\text { - Se deben establecer criterios de evaluación coherentes con } \\
\text { los objetivos de aprendizaje, y las competencias básicas pre- } \\
\text { vistas en el ámbito de una educación científica básica }\end{array}$ \\
\hline
\end{tabular}



INVE STIGACIÓN DIDÁCTICA

\title{
Hombres y mujeres ante su formación universitaria. Expectativas de éxito en estudios científico-tecnológicos y barreras percibidas
}

\author{
Carmen María Fernández García, Susana Torío López Universidad de Oviedo* \\ y Omar García Pérez
}

RESUMEN: Existen diversos factores que condicionan las elecciones académicas y profesionales de los estudiantes, así como sus creencias de autoeficacia en el afrontamiento de su formación. El presente artículo analiza algunos de estos factores con una amplia muestra de estudiantes universitarios de Grado de estudios científicos y tecnológicos. Los resultados indican algunas diferencias de comportamiento entre los diversos Grados, un optimismo generalizado en sus expectativas de éxito a pesar de reconocer que tendrán ciertas dificultades de comprensión así como, en algunos casos, una percepción de haber experimentado alguna discriminación por motivo de género.

Palabras clave: Género; Ciencia; Estudios universitarios; Autoeficacia.

ABSTRACT: Men and women towards higher education: expectations of success in scientific-technological studies and perceived barriers.

Students' academic and vocational choices and their self-efficacy beliefs in coping with their training are influenced by several factors. This article discusses some of these factors in a sample of students of Higher Education who are studying science and technology studies. The results show some differences in behaviour between the different Bachelor Degrees and a general optimism in their expectations of success. In spite of this, the students expect to have some difficulties in comprehension and, in some cases, they recognise having experienced certain discrimination based on their gender.

KeYwords: Gender; Science; Higher Education; Self- efficacy.

RÉSUMÉ: Hommes et femmes devant sa formation universitaire. Expectatives de succès dans des études scientifique-technologiques et les barriers perçues.

II y a plusieurs facteurs qui influencent les choix scolaires et professionnels des étudiants aussi bien que leurs croyances sur l'auto-efficacité pour faire face à leur formation. Cet article analyse certains de ces facteurs dans un large échantillon d'étudiants universitaires de Licence en études scientifiques et technologiques. Les résultats montrent quelques différences de comportement entre les divers Licences, un optimisme généralisé dans leurs attentes de succès, tout en reconnaissant qu'ils auront des difficultés de compréhension, et dans certains cas, la perception d'avoir été victimes de quelque sorte de discrimination de genre.

Mots clé: Genre; Science; Études universitaires; Auto-efficacité.

\footnotetext{
"Facultad de Formación de Profesorado y Educación. Universidad de Oviedo. Dirección de contacto: Carmen María Fernández García. Departamento de Ciencias de la Educación. C/ Aniceto Sela s/n, Despacho 235. 33005 Oviedo (España). Correo electrónico: fernandezcarmen@uniovi.es ๑rtículo recibido el 18 de Marzo de 2013 y aceptado el 24 de Enero de 2014.
} 


\section{Introducción}

En los últimos años se han desarrollado numerosos estudios e investigaciones para trata de determinar las razones que llevan a los estudiantes de enseñanza secundaria postobligatoria a elegir unos determinados estudios universitarios frente a otros, las especialidades por las que se muestra una mayor preferencia o e rendimiento obtenido en las diversas materias.

El Grupo de Investigación ASOCED (Grupo de Análisis Sociológico y Cultural de los Procesos Escolares y Educativos) es partícipe de este interés por conocer los argumentos en los que los estudiantes se basan para tomar este tipo de decisiones, emprendiendo para ello diversas investigaciones (Fernández et al., 2006 Rodríguez-Menéndez et al., 2006; Fernández et al., 2007; López et al., 2007).

En la actualidad, el grupo trata de determinar las diferencias de género que pueden estar mediando en estos itinerarios mediante una investigación que estudia la influencia de la autoeficacia en el rendimiento académico y en la elección de estudios científico-tecnológicos de los estudiantes de secundaria y universidad. Se trata de un proyecto financiado por el $\mathrm{Mi}$ nisterio de Ciencia e Innovación iniciado en el año 2010 y que finalizará en el año 2013. En el presente artículo nos centraremos únicament en el análisis de los datos obtenidos a partir de las respuestas de los estudiantes de la Universidad focalizando nuestra atención de manera particular, en la variable que denominaremo "persuasión y apoyo social". De manera más concreta, se pretende: 1) analizar las expectativas de éxito de los estudiantes; 2) profundizar en el influjo de la variable que denominaremos "persuasión y apoyo social" y 3) conocer la influencia de la variable género en todo ello.

\section{Género, estudios universitarios y futura salida profesional}

Uno de los elementos que puede condicionar las elecciones de los estudiantes en su acceso a la Universidad, en las materias opta- tivas por las que se inclinan o incluso en las futuras elecciones profesionales, es la creencia de que existen diferencias de género en la habilidad o facilidad para el aprendizaje y desempeño en determinadas actividades. Una de las más extendidas es la que considera que los hombres tienen una dotación "natural" para las ciencias o las matemáticas mientras, por el contrario, las mujeres la tendrían para las actividades vinculadas con el lenguaje o las cuestiones de orden social. Sin embargo, como han planteado las revisiones realizadas por algunos estudios (Erwin y Maurutto, 1998; Guimond y Roussel, 2001; Martín-Del Buey y Camarero-Suárez, 2001) esta afirmación no se sustenta en todas las investigaciones empíricas desarrolladas recientemente. Incluso puede afirmarse que no existiría tal competencia o incompetencia entendida de una forma general sino que, ya desde edades tempranas, puede constatarse que dentro de la competencia científica hay cualidades en las que los hombres obtienen mejores resultados mientras que en otras dimensiones son las mujeres las que se ubican en las primeras posiciones (MarbáTallada y Solsona-Pairó, 2012). Parece además que estas diferencias se explicarían más por el proceso de socialización diferenciado que han vivido cada uno de los géneros, los valores que el sujeto pueda ir incorporando en su trayectoria vital - escolar o aspectos motivadores/ desmotivadores ante determinadas tareas, que por verdaderas diferencias cognitivas explicables mediante factores puramente biológicos (Ayalon, 2003; Bermúdez et al., 2011; BlättelMink, 2002; Evers et al., 2006; García-Gómez et al., 2009; Marbá-Tallada y Solsona-Pairó, 2012; Martín-Del Buey y Camarero-Suárez, 2001; Rodd y Bartholomew, 2006; Rego y Castro, 2002; Sax y Harper, 2007). Por lo tanto, se concluye que este proceso de socialización es construido desde las diversas esferas en las que los sujetos se desenvuelven: su ambiente familiar más próximo, el influjo de los iguales, la repercusión de las instituciones académicas y sus docentes, los mensajes que la sociedad transmite a través de sus medios de comunicación, etc
En todo caso, con independencia de esta comprobación parece necesario tener muy en mujeres se encuentran más presionadas y obtienen peores resultados cuando se encuentran preocupadas por confirmar el estereotipo que las sitúa como peor dotadas para lo científicomatemático. Así, llegan incluso en ocasiones considerar que si obtienen mejores resultados que los varones en estos ámbitos, es debido factores externos tales como que el nivel de 2002; Guimond y Roussel, 2001), que poseen una gran memoria -no se menciona la habilidad- (Rodd y Bartholomew, 2006) o el convencimiento de que son menos capaces que sus compañeros varones (Erwin y Maurutto, 1998 Guimond y Roussel, $2001^{1}$ ) aun cuando sus resultados no corroboren esta percepción. Por lo tanto, en algunos casos, los varones y las mujeres con un fuerte estereotipo de género suelen percibirse como más dotados para las ciencias o lengua respectivamente (Guimond y Roussel, 2001) que aquéllos que no poseen un estereotipo de género tan intenso.

La teoría social cognitiva de la carrera desarrollada por Lent y colaboradores trabaja esto condicionantes y establece que las creencias de autoeficacia son junto con otras variables, de cisivas en la elección vocacional. Así, el interés por la materia, las expectativas de resultados las metas o intentos para persistir en una actividad o el apoyo/barreras sociales serían de terminantes en el proceso de decisión acadé mica y vocacional. Por expresarlo de un modo más clarificador, sería posible afirmar que las personas forman sus creencias de autoeficacia interpretando la información que obtienen de cuatro fuentes o recursos fundamentales (Betz y Borgen, 2000; Britner y Pajares, 2006; Hacket y Betz, 1981; Lent et al., 1996; Miura, 1987; Pajares, 2005; Zeldin y Pajares, 2000; Zeldin et al. 2008). Éstas serían las siguientes: cuenta esta creencia "biologicista" pues, las exigencia en su caso es inferior (Blättel-Mink

1. Experiencias previas: los estudiantes realizan tareas e interpretan los resultados de sus acciones, y usan esta información para desarrollar creencias sobre su competencia para el afrontamiento de tareas similares. Normalmente, experiencias previas de éxito ayudan a incrementar la autoeficacia; al contrario, las que conducen al fracaso provocan una disminución de la autoeficacia.

2. Modelado y aprendizaje vicario: los estudiantes también forman sus creencias de autoeficacia observando a otros mientras realizan dichas tareas y comparando su propia competencia con la de esas personas. Para que este recurso ejerza su influencia, el modelo observado debe poseer características personales similares a las del observador. De este modo, la persona puede imaginar que "si él/ella puede hacerlo, yo también soy capaz".

3. Persuasión y apoyo social: este recurso supone la exposición a los juicios, verbales y no verbales de otras personas significativas para el individuo. La persuasión social positiva puede ayudar a aumentar las creencias sobre la propia competencia y, al contrario, los refuerzos y estímulos negativos pueden desarrollar el sentido de la propia incapacidad. Puesto que la sociedad ha definido los patrones de conducta socialmente deseables para cada uno de los sexos, varones y mujeres reciben mensajes positivos y negativos cuando realizan determinadas elecciones académicas. Estos mensajes provienen del entorno social y son los progenitores, docentes y amigos/amigas quienes ejercen la mayor influencia a través de los mecanismos de persuasión social.

4. Estado de arousal: el estado emocional que experimenta una persona cuando contempla o realiza una tarea influye en la formación de las creencias de autoeficacia. Si hay estrés y ansiedad, estas creencias pueden ser bajas, mientras que serán altas si la persona está relajada.

1 Paradójicamente en este mismo estudio se observa que los varones, sin embargo, consideran que la dotación de hombres y mujeres para las ciencias es igual (Guimond y Roussel, 2001). Esta misma apreciación en cuanto a la igualdad o preferencia de hombres y mujeres por las matemáticas se pone de manifiesto en Rodd y Bartholomew (2006). 
Por tanto, las personas elaboramos nuestras creencias de autoeficacia a través de la interpretación de la información que recibimos de los cuatro recursos mencionados. La relevancia de cada uno de ellos en la formación de tales creencias dependerá de la materia o actividad y del proceso de integración que efectúe cada persona (Pajares, 2005; Zeldin et al., 2008). Así, por ejemplo, en lo que respecta a las matemáticas, se ha demostrado que las experiencias previas, la persuasión socia y el estado de arousal correlacionan entre ellos de forma muy significativa. En cuanto al apren dizaje vicario, se concluyó que estaba moderadamente relacionado con la persuasión social $y$ tenía una correlación muy baja con las otras do variables (Lent, López, Brown y Gore, 1996).

En este contexto, diversos autores (Bandura et al., 2001; Betz y Hackett, 1981, 1997, 2006; Betz y Schifano, 2000; Hackett, 1985; Hackett y Betz, 1981; Olaz, 2003; Vouillot et al., 2004 Zeldin y Pajares, 2000) han indicado que las creencias de autoeficacia tienen un peso especí fico muy importante para explicar el desarrollo de la carrera de las mujeres. Se postula que no desarrollan altas creencias de autoeficacia para las disciplinas científico-tecnológicas y este hecho explica su menor presencia en ellas.

\section{Material y método}

\section{Muestra}

En la investigación han participado 813 estudiantes que cursan su segundo año de carrer en distintas especialidades de los Grados de Ingeniería y estudios de Ciencias en la Universidad de Oviedo (289 chicas y 522 chicos, lo que representa un $36 \%$ y $64 \%$ del total de la muestra respectivamente). Sus edades se encuentran comprendidas entre los 18 y 37 años $(M e$ dia=19,72 y D.T.=1.9). La variable edad tení una asimetría negativa y era leptocúrtica, por lo que se consideró emplear la prueba $U$ de ManWhitney para determinar si había diferencia estadísticamente significativas entre chicos chicas. Los resultados mostraron que existían tales diferencias $(\mathrm{U}=54336,5, \mathrm{p}=0.001)$.
En las chicas, la edad media es de 19 años con una D.T.=1.77; en los chicos la edad media es de 20 años con una D.T.=2. El rango de edad en las mujeres oscila entre los 18 y 29 años, mientras que en los hombres el rango es de 18 hasta 37 años.

La distribución por género y estudios muestra (Tabla 1) una relación estadísticamente significativa entre ambas $(\chi 2=319,44, p=0.00$; Coeficiente de Contingencia $=0.53, p=0.00$ ). En casi todas las especialidades son mayoría los chicos, menos en Química Industrial, donde las chicas les doblan en número (68.4\% frente a 31.6\%), Biotecnología (57.9\% frente a 42,1\%), Química ( $54.3 \%$ frente a $45.7 \%$ ), Biología ( $57.8 \%$ y $42.2 \%$ ) y en Matemáticas donde las chicas llegan casi a cuadriplicar a sus compañeros varones $(79.1 \%$ frente a 20.9\%). La presencia masculina es especialmente patente en la mayoría de las especialidades de Ingeniería y de manera muy particular en Informática en Tecnologías de la Información (93,5\%), Informática del Software (87\%) e Ingeniería Forestal y del Medio Natural (85,7\%).

A efectos de algunos de análisis estadísticos se ha categorizado en algún caso la muestra en dos grandes grupos: Ingenierías y Ciencias. Dentro de la primera se incluirían los estudiantes de las diversas especialidades de Tecnología o de Ingeniería y dentro de la segunda los estudios de Geología, Biotecnología, Química, Física, Biología y Matemáticas. La fragmentación de la muestra en estos dos grupos obedece a razones que han sido fruto de un análisis y reflexión riguroso. En efecto, los estudios estadísticos iniciales realizados como aproximación exploratoria a la muestra, han permitido concluir que existen importantes variaciones entre estos dos grupos en cuanto a sus preferencias profesionales y expectativas académicas

\section{Procedimiento e instrumentos}

En el proceso de recogida de información de los estudiantes correspondientes a la muestra universitaria, estos completaron un cuestionario durante una clase del primer semestre del curso académico. Este cuestionario, que contestaron de

\begin{tabular}{|l|l|l|l|}
\cline { 2 - 4 } \multicolumn{1}{c|}{} & \multicolumn{1}{c|}{$\begin{array}{c}\text { CHICAS } \\
\text { (N=163) }\end{array}$} & $\begin{array}{c}\text { CHICOS } \\
(\mathrm{N}=4 \mathbf{4 1 6})\end{array}$ & TOTAL \\
\hline Eléctrica & $7(29.2 \%)$ & $17(70.8 \%)$ & $24(2.9 \%)$ \\
\hline Electrónica Industrial y Automática & $9(25 \%)$ & $27(75 \%)$ & $36(4.4 \%)$ \\
\hline Química Industrial & $13(68.4 \%)$ & $6(31.6 \%)$ & $19(2.3 \%)$ \\
\hline Mecánica & $23(24.5 \%)$ & $71(75.5 \%)$ & $94(11.6 \%)$ \\
\hline Tecnologías Industriales & $22(25 \%)$ & $66(75 \%)$ & $88(10.8 \%)$ \\
\hline Tecnología y Servicios de Telecomunicación & $21(32.3 \%)$ & $44(67.4 \%)$ & $65(7.9 \%)$ \\
\hline Informática en Tecnologías de la Información & $2(6.5 \%)$ & $29(93.5 \%)$ & $31(3.8 \%)$ \\
\hline Tecnología Mineras & $19(38.8 \%)$ & $30(61.2 \%)$ & $49(6 \%)$ \\
\hline Informática del Software & $10(13 \%)$ & $67(87 \%)$ & $77(9.5 \%)$ \\
\hline Recursos Mineros y Energéticos & $15(38.5 \%)$ & $24(61.5 \%)$ & $39(4.8 \%)$ \\
\hline Geomática y Topografía & $9(45 \%)$ & $11(55 \%)$ & $20(2.5 \%)$ \\
\hline Forestal y del Medio Natural & $2(14.3 \%)$ & $12(85.7 \%)$ & $14(1.7 \%)$ \\
\hline Ingeniería Química & $11(47.8 \%)$ & $12(52.2 \%)$ & $23(2.8 \%)$ \\
\hline Geología & $11(47.8 \%)$ & $12(52.2 \%)$ & $23(2.8 \%)$ \\
\hline Biotecnología & $11(57.9 \%)$ & $8(42.1 \%)$ & $19(2.3 \%)$ \\
\hline Química & $25(54.3 \%)$ & $21(45.7 \%)$ & $46(5.6 \%)$ \\
\hline Física & $8(26.7 \%)$ & $22(73.3 \%)$ & $30(3.7 \%)$ \\
\hline Biología & $52(57.8 \%)$ & $38(42.2 \%)$ & $90(11 \%)$ \\
\hline Matemáticas & $19(79.1 \%)$ & $5(20.9 \%)$ & $24(2.9 \%)$ \\
\hline
\end{tabular}

Tabla 1. Distribución por género y estudios.

manera voluntaria y anónima, fue administrado personalmente por el equipo de investigación.

El cuestionario constaba de un total de 77 ítems y ha sido el resultado de una traducción y adaptación a la población española del instrumento Engineering Fields Questionnaire. La versión original del instrumento fue solicitada y posteriormente enviada al equipo por el propio autor, Robert W. Lent de la Universidad de Maryland. Antes de proceder a su aplicación, se realizó el proceso de traducción del idioma inglés al español, tomándose las medidas oportunas para adaptar expresiones lingüísticas del inglés americano que no están presentes en la cultura académica española. Cabe resaltar que, si bien inicialmente se decidió usar la metodología «backward translation», realizando la traducción del inglés al español y traduciendo la nueva versión castellana al inglés, sin embargo, debido a que los autores del instrumento original no dominaban el idioma español, fue necesario reconsiderar esta decisión, optando por un proceso de traducción «forward translation».

Este instrumento permite medir variables como: creencias de autoeficacia (5 items), expectativas de resultado (10 items), interés por los estudios cursados (2 items), metas (10 items), barreras y apoyos sociales (17 items). 
Para medir las creencias de autoeficacia se incluyó una subescala ( $1=$ nada de confianza a $9=$ absoluta confianza) que preguntaba por su grado de confianza para cursar con éxito lo estudios que estaban realizando (Coeficiente $\alpha=.88)$. Para medir las expectativas de resultado, se incluyeron ítems en los que se indagaba sobre la opinión que tenían acerca de la relevancia de los estudios elegidos para sus planes profesionales (escala 1 a 9) (Coeficiente $\alpha=.88$ ). La variable "interés por los estudios cursados" fue medida con ítems referidos al interés por estudiar determinados tópicos y realizar actividades de ciencia y tecnología (escala 1 a 5 ) (Coeficiente $\alpha=.82$ ). Para la variable "metas", se introdujeron ítems para medir los intentos por persistir en los estudios elegidos (escala a 5) (Coeficiente $\alpha=.88$ ). Las barreras y apoyo sociales fueron medidos mediante ítems en lo que debían indicar el refuerzo que obtenían de distintos elementos que facilitaban/dificultaban su trayectoria formativa (escala 1 a 5 ) (Coeficiente $\alpha=.82$ ). Para una información más exhaustiva sobre la estructura interna del instrumento y validación del instrumento pued consultarse Rodríguez-Menéndez et al. (2015).

\section{Análisis de Dato}

En el presente artículo nos hemos centrado en el análisis de algunos de los ítems que ofrecen información directa sobre los tres objetivo

principales del estudio mediante el programa estadístico SPSS. Así, se ha realizado análisis de frecuencias para conocer la distribución de la muestra en los distintos ítems, prestando especial atención a las variaciones entre estudiantes de Ciencias e Ingeniería. También se han llevado a cabo análisis de contingencias para verificar si existían diferencias significativas entre algunos de los ítems y la variable género.

\section{Resultados}

Una primera cuestión interesante para nuestro análisis es el grado de optimismo manifestado por los estudiantes en relación a sus posibilidades de éxito en los estudios. Como puede apreciarse en la Tabla 2 salvo un porcentaje muy ajustado de alumnos la mayoría de los estudiantes confían en permanecer matriculados en este curso, destacando que la mayoría de los estudiantes $(88.7 \%)$ se ubican en la categoría que más fehacientemente considera que continuará matriculado en sus estudios. Apreciamos, por tanto, que parece haber una diferencia notable respecto a la situación que la literatura pedagógica afirma que se produce en el primer curso de los estudios universitarios y, por la cual, un buen número de estudiantes se plantean muy seriamente la posibilidad de cambiar de estudios o incluso abandonar por completo su formación universitaria (Feldman, 2005). Una situación bastante semejante se aprecia cuando tratamos

\begin{tabular}{|c|c|c|c|c|c|c|c|c|c|c|}
\hline \multirow{3}{*}{$\begin{array}{l} \\
\text { Pienso } \\
\text { permanecer } \\
\text { matriculado en } \\
\text { este Grado }\end{array}$} & \multicolumn{2}{|c|}{$\begin{array}{l}\text { TOTALMENTE EN } \\
\text { DESACUERDo }\end{array}$} & \multicolumn{2}{|c|}{$\begin{array}{l}\text { Más bien en } \\
\text { Desacuerdo }\end{array}$} & \multicolumn{2}{|c|}{$\begin{array}{c}\text { No estoy } \\
\text { Seguro }\end{array}$} & \multicolumn{2}{|c|}{ De ACUERdo } & \multicolumn{2}{|c|}{$\begin{array}{c}\text { TOtalmente DE } \\
\text { ACuerdo }\end{array}$} \\
\hline & \multicolumn{2}{|c|}{$3(0.4 \%)$} & \multicolumn{2}{|c|}{$2(0.2 \%)$} & \multicolumn{2}{|c|}{$15(1.8 \%)$} & \multicolumn{2}{|c|}{$71(8.7 \%)$} & \multicolumn{2}{|c|}{$721(88.7 \%)$} \\
\hline & $\begin{array}{l}\text { I } \\
3\end{array}$ & $\begin{array}{l}\text { C } \\
-\end{array}$ & $\begin{array}{l}\text { I } \\
2\end{array}$ & $\begin{array}{l}\mathrm{C} \\
-\end{array}$ & $\begin{array}{c}\text { I } \\
12\end{array}$ & $\begin{array}{l}\text { C } \\
3\end{array}$ & $\begin{array}{c}\text { I } \\
53\end{array}$ & $\begin{array}{c}\text { C } \\
18\end{array}$ & $\begin{array}{c}\text { I } \\
510\end{array}$ & $\begin{array}{c}\mathbf{C} \\
211\end{array}$ \\
\hline \multirow{2}{*}{$\begin{array}{l}\text { Pienso que } \\
\text { conseguir } \\
\text { el Grado es } \\
\text { un objetivo } \\
\text { realista para mí }\end{array}$} & \multicolumn{2}{|c|}{$1(0.1 \%)$} & \multicolumn{2}{|c|}{$2(0.2 \%)$} & \multicolumn{2}{|c|}{$34(4.2 \%)$} & \multicolumn{2}{|c|}{$185(22.8 \%)$} & \multicolumn{2}{|c|}{$590(72.7 \%)$} \\
\hline & $\begin{array}{l}\text { I } \\
1\end{array}$ & $\begin{array}{l}\mathrm{C} \\
-\end{array}$ & $\begin{array}{l}\text { I } \\
2\end{array}$ & $\begin{array}{l}\mathrm{C} \\
-\end{array}$ & $\begin{array}{c}\text { I } \\
27\end{array}$ & $\begin{array}{l}\text { C } \\
7\end{array}$ & $\begin{array}{c}\text { I } \\
131\end{array}$ & $\begin{array}{l}\mathrm{C} \\
54\end{array}$ & $\begin{array}{c}\mathbf{I} \\
419\end{array}$ & $\begin{array}{c}\mathbf{C} \\
171\end{array}$ \\
\hline
\end{tabular}

Tabla 2. Optimismo de los estudiantes respecto a su continuidad en el Grado. de determinar si se consideran capaces de finalizar sus estudios universitarios: solamente un $0.1 \%$ manifiestan estar «Totalmente en desacuerdo», un $0.2 \%$ «Más bien en desacuerdo» «No están seguros» un $4.2 \%$.

En la Tabla 2 se presentan además desglosadas las respuestas de los dos grandes grupo en los que se ha dividido a los estudiantes: Ingeniería (I) y Ciencias (C). Como puede apreciarse, son siempre estudiantes del primero de los grupos los que se ubican en las opciones de respuesta que suponen que tendrán mayore dificultades tanto en continuar sus estudio durante ese semestre como en ser capaces de culminarlos. Igualmente, dentro de cada uno de los grupos las respuestas más optimistas son ligeramente superiores en los estudiantes $\mathrm{d}$ ciencias. Estos datos nos ofrecen pistas que será necesario explorar con mayor profundidad en el momento en el que se emprenda la fase cua- litativa de la investigación. En efecto, conviene estudiar exhaustivamente los apoyos que perciben los estudiantes -y especialmente los de ingenierías- procedentes de su ambiente familiar o del entorno académico.

En todo caso, dados los antecedentes encontrados en la revisión de la literatura pedagógica dizar en la variable género, encontrando datos sorprendentes. A saber, en toda la muestra se observa una relación estadísticamente significativa (Coeficiente de Contingencia $=0.332, \mathrm{p}=$ 0.000 ) entre el ítem referido a terminar el Grado y otro pregunta del instrumento en el que se hacía referencia a si los estudiantes se «sienten diferentes al resto por motivo de género» (Ver Tabla 3). Más aún, también se aprecia esta relación entre su expectativa de finalizar los estudios y su consideración de que han recibido un trato injusto por su género en los primeros sobre este particular, hemos querido profun-

\begin{tabular}{|c|c|c|c|c|c|c|c|c|c|c|c|}
\hline & & Posi & LIDA & $\mathrm{SEI}$ & RME & ERE & $\mathrm{AL}$ & $\mathrm{OP}$ & MOI & $\mathrm{O} \mathrm{DE}$ & NERO \\
\hline & & & una & & & & & & & Mu & sible \\
\hline \multirow{10}{*}{$\begin{array}{l}\text { Pienso que } \\
\text { conseguir } \\
\text { el Grado es } \\
\text { un objetivo } \\
\text { realista } \\
\text { para mí }\end{array}$} & \multirow[b]{2}{*}{$\begin{array}{l}\text { Totalmente en } \\
\text { desacuerdo }\end{array}$} & \multicolumn{2}{|c|}{0} & \multicolumn{2}{|c|}{0} & \multicolumn{2}{|c|}{$1(100 \%)$} & \multicolumn{2}{|c|}{0} & \multicolumn{2}{|c|}{0} \\
\hline & & $\begin{array}{l}\mathrm{I} \\
-\end{array}$ & $\mathrm{C}$ & $\begin{array}{l}\text { I } \\
-\end{array}$ & $\begin{array}{l}\mathrm{C} \\
-\end{array}$ & $\begin{array}{l}\mathrm{I} \\
1\end{array}$ & $\begin{array}{l}\mathrm{C} \\
-\end{array}$ & I & $\begin{array}{l}\mathrm{C} \\
-\end{array}$ & I & $\begin{array}{l}\mathrm{C} \\
-\end{array}$ \\
\hline & \multirow{2}{*}{$\begin{array}{l}\text { Más bien en } \\
\text { desacuerdo }\end{array}$} & \multicolumn{2}{|c|}{$1(50 \%)$} & \multicolumn{2}{|c|}{0} & \multicolumn{2}{|c|}{0} & \multicolumn{2}{|c|}{0} & \multicolumn{2}{|c|}{$1(50 \%)$} \\
\hline & & $\begin{array}{l}\mathrm{I} \\
1\end{array}$ & C & $\begin{array}{l}\text { I } \\
-\end{array}$ & $\begin{array}{l}\mathrm{C} \\
-\end{array}$ & $\begin{array}{l}\mathrm{I} \\
-\end{array}$ & $\begin{array}{l}\text { C } \\
-\end{array}$ & $\begin{array}{l}\text { I } \\
-\end{array}$ & $\begin{array}{l}\mathrm{C} \\
-\end{array}$ & $\begin{array}{l}\text { I } \\
1\end{array}$ & $\begin{array}{l}\text { C } \\
-\end{array}$ \\
\hline & \multirow{2}{*}{$\begin{array}{l}\text { No estoy } \\
\text { seguro }\end{array}$} & \multicolumn{2}{|c|}{$\begin{array}{c}18 \\
(53 \%)\end{array}$} & \multicolumn{2}{|c|}{$\begin{array}{c}3 \\
(8.9 \%)\end{array}$} & \multicolumn{2}{|c|}{$\begin{array}{c}9 \\
(26.4 \%)\end{array}$} & \multicolumn{2}{|c|}{$\begin{array}{c}3 \\
(8.9 \%)\end{array}$} & \multicolumn{2}{|c|}{$\begin{array}{c}1 \\
(3 \%)\end{array}$} \\
\hline & & $\begin{array}{c}\mathrm{I} \\
12\end{array}$ & $\begin{array}{l}\text { C } \\
6\end{array}$ & $\begin{array}{l}\text { I } \\
2\end{array}$ & $\begin{array}{l}C \\
1\end{array}$ & $\begin{array}{l}\text { I } \\
9\end{array}$ & $\begin{array}{l}C \\
-\end{array}$ & $\begin{array}{l}\text { I } \\
3\end{array}$ & $\begin{array}{l}C \\
-\end{array}$ & $\begin{array}{l}\mathrm{I} \\
1\end{array}$ & $\begin{array}{l}C \\
-\end{array}$ \\
\hline & \multirow{2}{*}{ De acuerdo } & \multicolumn{2}{|c|}{$\begin{array}{c}156 \\
(84.8 \%)\end{array}$} & \multicolumn{2}{|c|}{$\begin{array}{c}11 \\
(6 \%)\end{array}$} & \multicolumn{2}{|c|}{$\begin{array}{c}8 \\
(4.3 \%)\end{array}$} & \multicolumn{2}{|c|}{$\begin{array}{c}7 \\
(3.9 \%)\end{array}$} & \multicolumn{2}{|c|}{$\begin{array}{c}2 \\
(1 \%)\end{array}$} \\
\hline & & $\begin{array}{c}\mathrm{I} \\
105\end{array}$ & $\begin{array}{c}\mathrm{C} \\
51\end{array}$ & $\begin{array}{l}\text { I } \\
8\end{array}$ & $\begin{array}{l}\mathrm{C} \\
3\end{array}$ & $\begin{array}{l}\text { I } \\
8\end{array}$ & $\begin{array}{l}\mathrm{C} \\
-\end{array}$ & $\begin{array}{l}\text { I } \\
7\end{array}$ & $\begin{array}{l}\mathrm{C} \\
-\end{array}$ & $\begin{array}{l}\text { I } \\
2\end{array}$ & $\begin{array}{l}\mathrm{C} \\
-\end{array}$ \\
\hline & \multirow{2}{*}{$\begin{array}{l}\text { Totalmente de } \\
\text { acuerdo }\end{array}$} & \multicolumn{2}{|c|}{$\begin{array}{c}502 \\
(85.2 \%)\end{array}$} & \multicolumn{2}{|c|}{$\begin{array}{c}42 \\
(7.1 \%)\end{array}$} & \multicolumn{2}{|c|}{$\begin{array}{c}29 \\
(5 \%)\end{array}$} & \multicolumn{2}{|c|}{$\begin{array}{c}11 \\
(1.9 \%)\end{array}$} & \multicolumn{2}{|c|}{$\begin{array}{c}5 \\
(0.9 \%)\end{array}$} \\
\hline & & $\begin{array}{c}\text { I } \\
347\end{array}$ & $\begin{array}{c}\mathrm{C} \\
155\end{array}$ & $\begin{array}{c}\mathrm{I} \\
33\end{array}$ & $\begin{array}{l}\mathrm{C} \\
9\end{array}$ & $\begin{array}{c}\mathrm{I} \\
27\end{array}$ & $\begin{array}{l}\mathrm{C} \\
2\end{array}$ & $\begin{array}{l}\text { I } \\
9\end{array}$ & $\begin{array}{l}\mathrm{C} \\
2\end{array}$ & $\begin{array}{l}\text { I } \\
2\end{array}$ & $\begin{array}{l}\mathrm{C} \\
3\end{array}$ \\
\hline
\end{tabular}

Tabla 3. Optimismo de los estudiantes respecto finalización del Grado y sentimiento diferente por género. 


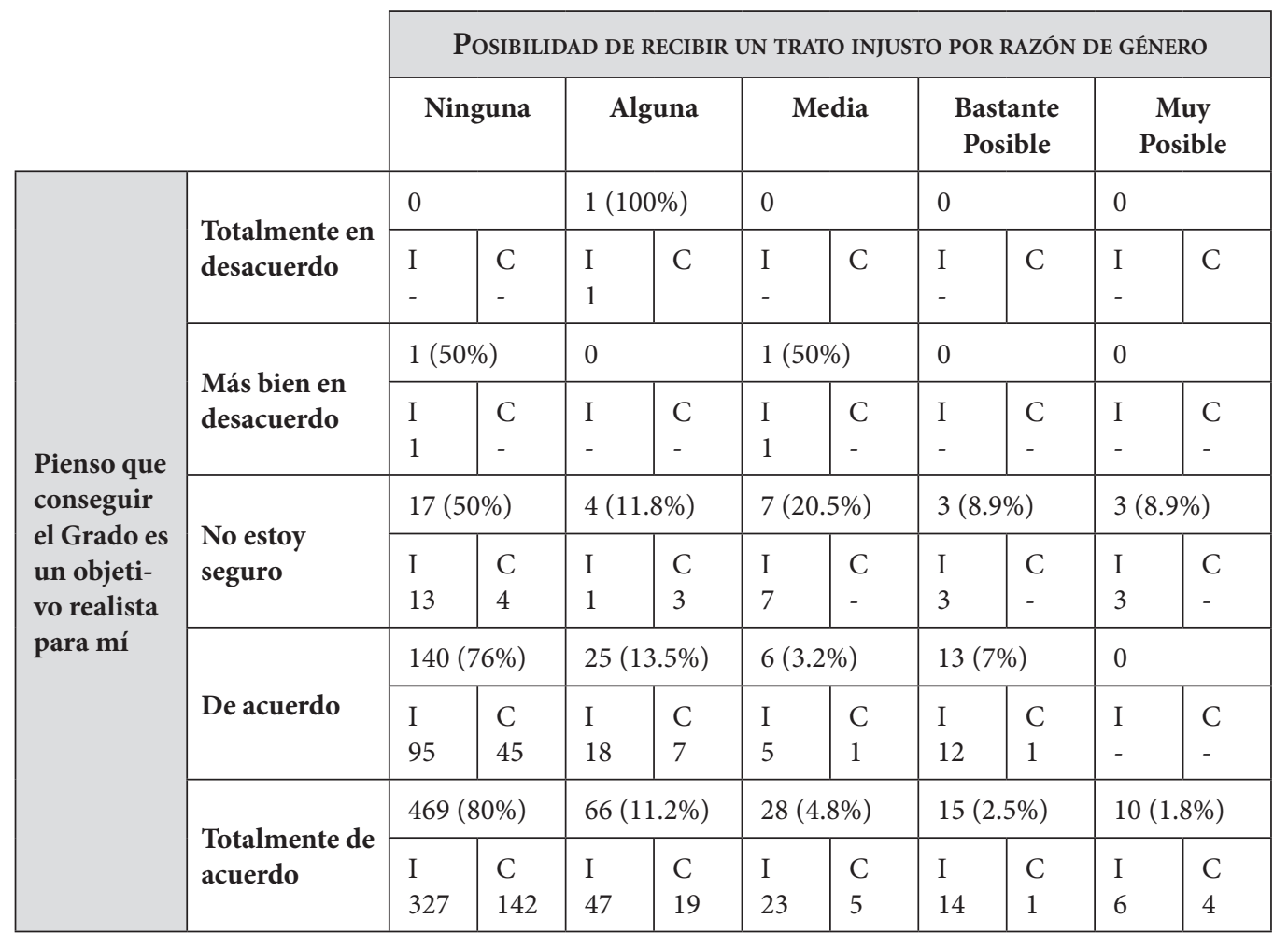

Tabla 4. Optimismo de los estudiantes respecto finalización del Grado y trato injusto por razón de género.

años de carrera (Coeficiente de Contingencia= $0.265, \mathrm{p}=0.000$ ) como puede constatarse en la Tabla 4. .

Sin embargo, en contra de lo que plantean muchos estudios no parece que ni alumnos $n$ alumnas perciban que el nivel de exigencia de los estudios vaya a interferir en sus responsabilidades familiares (cuidado de hijos, persona dependientes u otras), refrendándose en que no hay una relación estadísticamente significativa entre dos ítems del cuestionario que se incluían en el instrumento de recogida de información (Tablas 5 y 6 respectivamente ), respecto a esta dificultad de conciliación («Percibir que las demandas que supone continuar en este grado interferirán en mis responsabilidades familiares» -Coeficiente de Contingencia= $0.128, p=0.195-y$, «Estar preocupado por que esta carrera profesional requerirá mucho tiempo y formación»-Coeficiente de Contingencia $=0.125, p=0.116-$ ). Sería interesant

contrastar estos datos con sus respuestas ante estas mismas preguntas cuando estos alumnos se encuentren a punto de finalizar sus estudios universitarios y cuando, por tanto, visualicen de una manera más clara la necesidad de tomar decisiones profesionales inmediatas.

Sin embargo, y ésta es una cuestión que debería preocuparnos como docentes, inquieta su percepción acerca de las dificultades de comprensión o su impresión de tener malos docentes (Ver Tabla 7). Así, del conjunto de la muestra menos de la mitad (48.6\%) responden con rotundidad que no se han sentido perjudicados por dificultades de comprensión (categorías «Totalmente en Desacuerdo» y «Más bien en Desacuerdo»). En este caso, la situación entre los estudiantes de ingeniería y de ciencias no reviste diferencias notables. Además, un 40,2\% del conjunto de la muestra está convencido de que se encontrará profesores poco competentes en sus estudios: así lo verifican un $19,5 \%$ que

\begin{tabular}{|c|c|c|c|c|c|c|c|c|c|c|c|}
\hline & & Perc & R QU & AS DE & $\begin{array}{l}\text { DDAS } \\
\text { ESPO }\end{array}$ & $\begin{array}{l}\text { SUP } \\
\text { BILII }\end{array}$ & $\begin{array}{l}\text { E CO } \\
\text { ES F }\end{array}$ & $\begin{array}{l}\text { UAR } \\
\text { IARI }\end{array}$ & ADO & ERF & ÁN EN \\
\hline & & & & & & & & & & & osible \\
\hline \multirow{4}{*}{ Género } & \multirow[b]{2}{*}{ Femenino } & \multicolumn{2}{|c|}{$148(51.5 \%)$} & \multicolumn{2}{|c|}{$65(22.7 \%)$} & \multicolumn{2}{|c|}{$50(17.4 \%)$} & \multicolumn{2}{|c|}{$19(6.6 \%)$} & \multicolumn{2}{|c|}{$5(1.8 \%)$} \\
\hline & & $\begin{array}{c}\text { I } \\
81\end{array}$ & $\begin{array}{l}\mathrm{C} \\
67\end{array}$ & $\begin{array}{c}\text { I } \\
37\end{array}$ & $\begin{array}{c}\mathrm{C} \\
28\end{array}$ & $\begin{array}{c}\text { I } \\
26\end{array}$ & $\begin{array}{c}\text { C } \\
24\end{array}$ & $\begin{array}{c}\text { I } \\
14\end{array}$ & $\begin{array}{l}C \\
5\end{array}$ & $\begin{array}{l}\mathrm{I} \\
4\end{array}$ & $\begin{array}{l}\mathrm{C} \\
1\end{array}$ \\
\hline & \multirow{2}{*}{ Masculino } & \multicolumn{2}{|c|}{$204(39.3 \%)$} & \multicolumn{2}{|c|}{$139(26.9 \%))$} & \multicolumn{2}{|c|}{$\begin{array}{c}123 \\
(23.8 \%)\end{array}$} & \multicolumn{2}{|c|}{$\begin{array}{c}44 \\
(8,4 \%)\end{array}$} & \multicolumn{2}{|c|}{$\begin{array}{c}8 \\
(1.5 \%)\end{array}$} \\
\hline & & $\begin{array}{c}\text { I } \\
156\end{array}$ & $\begin{array}{c}\mathrm{C} \\
48\end{array}$ & $\begin{array}{c}\text { I } \\
110\end{array}$ & $\begin{array}{c}C \\
29\end{array}$ & $\begin{array}{c}\text { I } \\
104\end{array}$ & $\begin{array}{c}C \\
19\end{array}$ & $\begin{array}{c}\text { I } \\
36\end{array}$ & $\begin{array}{l}C \\
8\end{array}$ & I & $\begin{array}{l}\mathrm{C} \\
1\end{array}$ \\
\hline
\end{tabular}

Tabla 5. Interferencia de los estudios con responsabilidades familiares y género.

\begin{tabular}{|c|c|c|c|c|c|c|c|c|c|c|c|}
\hline & \multicolumn{10}{|c|}{$\begin{array}{l}\text { ESTAR PREOCUPADO PORQUE ESTA CARRERA PROFESIONAL REQUERIRÁ MUCHO } \\
\text { TIEMPO Y FORMACIÓN }\end{array}$} \\
\hline & & \multirow{2}{*}{\multicolumn{2}{|c|}{$\begin{array}{l}\text { Ninguna } \\
28(9.7 \%)\end{array}$}} & \multirow{2}{*}{\multicolumn{2}{|c|}{$\begin{array}{c}\text { Alguna } \\
44(15.2 \%)\end{array}$}} & \multirow{2}{*}{\multicolumn{2}{|c|}{$\begin{array}{c}\text { Media } \\
92(31.9 \%)\end{array}$}} & \multirow{2}{*}{\multicolumn{2}{|c|}{$\begin{array}{c}\begin{array}{c}\text { Bastante } \\
\text { Posible }\end{array} \\
90(31.1 \%)\end{array}$}} & \multirow{2}{*}{\multicolumn{2}{|c|}{$\begin{array}{l}\text { Muy Posible } \\
35(12.1 \%)\end{array}$}} \\
\hline \multirow{4}{*}{ Género } & \multirow[b]{2}{*}{ Femenino } & & & & & & & & & & \\
\hline & & $\begin{array}{c}\mathrm{I} \\
13\end{array}$ & $\begin{array}{c}\mathrm{C} \\
15\end{array}$ & $\begin{array}{c}\mathrm{I} \\
16\end{array}$ & $\begin{array}{c}\mathrm{C} \\
28\end{array}$ & $\begin{array}{c}\text { I } \\
62\end{array}$ & $\begin{array}{c}\mathrm{C} \\
30\end{array}$ & $\begin{array}{c}\text { I } \\
54\end{array}$ & $\begin{array}{l}\mathrm{C} \\
36\end{array}$ & $\begin{array}{c}\mathrm{I} \\
18\end{array}$ & $\begin{array}{c}\mathrm{C} \\
17\end{array}$ \\
\hline & \multirow[b]{2}{*}{ Masculino } & \multicolumn{2}{|c|}{$73(14 \%)$} & \multicolumn{2}{|c|}{$112(21.6 \%)$} & \multicolumn{2}{|c|}{$158(30.5 \%)$} & \multicolumn{2}{|c|}{$126(24.3 \%)$} & \multicolumn{2}{|c|}{$49(9,4 \%)$} \\
\hline & & $\begin{array}{c}\text { I } \\
57\end{array}$ & $\begin{array}{c}C \\
16\end{array}$ & $\begin{array}{c}\text { I } \\
91\end{array}$ & $\begin{array}{c}\mathrm{C} \\
21\end{array}$ & $\begin{array}{c}\mathrm{I} \\
122\end{array}$ & $\begin{array}{c}C \\
36\end{array}$ & $\begin{array}{c}\mathrm{I} \\
102\end{array}$ & $\begin{array}{c}C \\
24\end{array}$ & $\begin{array}{c}\text { I } \\
41\end{array}$ & $\begin{array}{l}\mathrm{C} \\
8\end{array}$ \\
\hline
\end{tabular}

Tabla 6. Preocupación por el tiempo y formación que requerirá carrera profesional y género

\begin{tabular}{|c|c|c|c|c|c|c|c|c|c|c|}
\hline & \multicolumn{2}{|c|}{$\begin{array}{c}\text { Totalmente en } \\
\text { Desacuerdo }\end{array}$} & \multicolumn{2}{|c|}{$\begin{array}{l}\text { Más BIEN EN } \\
\text { DeSACUERDo }\end{array}$} & \multicolumn{2}{|c|}{$\begin{array}{l}\text { No estoy } \\
\text { Seguro }\end{array}$} & \multicolumn{2}{|c|}{ De Acuerdo } & \multicolumn{2}{|c|}{$\begin{array}{l}\text { Totalmente } \\
\text { DE ACuERDo }\end{array}$} \\
\hline \multirow{2}{*}{$\begin{array}{l}\text { Me he sentido } \\
\text { perjudicado por } \\
\text { dificultades de } \\
\text { comprensión, } \\
\text { docentes difíciles } \\
\text { de entender }\end{array}$} & \multicolumn{2}{|c|}{$153(18.8 \%)$} & \multicolumn{2}{|c|}{$242(29.8 \%)$} & \multicolumn{2}{|c|}{$197(24.3 \%)$} & \multicolumn{2}{|c|}{$146(18 \%)$} & \multicolumn{2}{|c|}{$72(8.9 \%)$} \\
\hline & $\begin{array}{c}\mathrm{I} \\
104\end{array}$ & $\begin{array}{l}\mathrm{C} \\
49\end{array}$ & $\begin{array}{c}\mathrm{I} \\
176\end{array}$ & $\begin{array}{l}C \\
66\end{array}$ & $\begin{array}{c}\mathrm{I} \\
128\end{array}$ & $\begin{array}{l}C \\
69\end{array}$ & $\begin{array}{c}\mathrm{I} \\
111\end{array}$ & $\begin{array}{c}\mathrm{C} \\
35\end{array}$ & $\begin{array}{c}\text { I } \\
59\end{array}$ & $\begin{array}{c}\mathrm{C} \\
13\end{array}$ \\
\hline \multirow{2}{*}{$\begin{array}{l}\text { Creo que tendré } \\
\text { posibilidades } \\
\text { de encontrarme } \\
\text { malos docentes en } \\
\text { las asignaturas de } \\
\text { la carrera }\end{array}$} & \multicolumn{2}{|c|}{$62(7.6 \%)$} & \multicolumn{2}{|c|}{$210(25.9 \%)$} & \multicolumn{2}{|c|}{$212(26.1 \%)$} & \multicolumn{2}{|c|}{$168(20.7 \%)$} & \multicolumn{2}{|c|}{$158(19.5 \%)$} \\
\hline & $\begin{array}{c}\text { I } \\
38\end{array}$ & $\begin{array}{l}C \\
24\end{array}$ & $\begin{array}{c}\mathrm{I} \\
141\end{array}$ & $\begin{array}{l}C \\
69\end{array}$ & $\begin{array}{c}\text { I } \\
146\end{array}$ & $\begin{array}{l}C \\
66\end{array}$ & $\begin{array}{c}\mathrm{I} \\
125\end{array}$ & $\begin{array}{c}C \\
43\end{array}$ & $\begin{array}{c}\mathrm{I} \\
128\end{array}$ & C 30 \\
\hline
\end{tabular}

Tabla 7. Opinión de los estudiantes respecto a dificultades académicas. 
sostienen estar «Totalmente de acuerdo» con esta afirmación y un 20,7\% que se ubican en la categoría «De acuerdo».

Ante estas dificultades podría ser de utilidad disponer de algún tipo de asesoramiento profesional. En efecto, la orientación educativa y profesional ya no se concibe en la actualidad como un proceso terminal que finaliza en el momento en el que se decide la opción de estudios postsecundarios que se va a realizar sino que se defiende una concepción mucho más amplia, que se desarrollará a lo largo de toda la vida y que cristaliza en los Planes de Acción Tutorial que la práctica totalidad de los centros han establecido como medidas de apoyo al proceso de Bolonia. Sorprenden por tanto las dudas de los estudiantes que se ubican en las categorías «Media» (30.7\%), «Alguna (8.9\%) y «Ninguna» (3.4\%) ante la pregunt que se centra en la posibilidad de recibir ayuda de un tutor/a en caso de necesitarlo (ver Tabla 8). En esta ocasión, parecen ser los estudiante de ingenierías los más pesimistas o los peor informados acerca de la presencia de tutores académicos o planes de acción tutorial que pueden contribuir a solventar sus indecisiones.

No obstante, como se refleja en la Tabla 8 resultan mucho más altos los porcentajes de estudiantes que consideran que no tendrán dificultades en recibir ayuda de otra posible fuente de información, sus docentes: el 20.3\% se posicionan en la respuesta «Ninguna di-

ficultad» y el $34.9 \%$ en «Alguna dificultad». Nuevamente, la percepción de los estudiantes de Ciencias parece más optimista que la de los estudiantes de ingeniería.

\section{Conclusiones}

Los estudiantes encuestados han mostrado tener importantes creencias de autoeficacia, reflejándose esta percepción en su confianza en continuar matriculados durante el curso académico en el que están actualmente así como, en un futuro más lejano, su convencimiento de que finalizarán los estudios de Grado que han iniciado. Los datos reflejan cómo los estudiantes de ingenierías obtienen unas puntuaciones más bajas que los estudiantes de ciencias en ambos ítems. En momentos posteriores de la investigación será necesario revisar si este optimismo se mantiene a lo largo del curso académico, cuando los resultados de los exámenes permitan tener quizás datos más objetivos del rendimiento que se está obteniendo (el cuestionario ha sido administrado durante el primer semestre).

De manera general no parece que ni la edad ni el género influyan en las respuestas a estas dos preguntas (continuar matriculado el semestre y finalizar los estudios. Además, la convicción de que finalizarán los estudios mantiene una relación estadísticamente significativa con haberse sentido diferente por motivo de

\begin{tabular}{|c|c|c|c|c|c|c|c|c|c|c|}
\hline \multirow{3}{*}{$\begin{array}{l}\text { Conseguir } \\
\text { ayuda un } \\
\text { tutor/a en } \\
\text { caso de que lo } \\
\text { necesitase }\end{array}$} & \multicolumn{2}{|c|}{ Ninguna } & \multicolumn{2}{|c|}{ Alguna } & \multicolumn{2}{|c|}{ Media } & \multicolumn{2}{|c|}{$\begin{array}{c}\text { Bastante } \\
\text { Posible }\end{array}$} & \multicolumn{2}{|c|}{ MuY POSIBLE } \\
\hline & \multicolumn{2}{|c|}{$28(3.4 \%)$} & \multicolumn{2}{|c|}{$72(8.9 \%)$} & \multicolumn{2}{|c|}{$249(30.7 \%)$} & \multicolumn{2}{|c|}{$307(37.8 \%)$} & \multicolumn{2}{|c|}{$156(19.2 \%)$} \\
\hline & $\begin{array}{c}\mathrm{I} \\
23\end{array}$ & $\begin{array}{l}\mathrm{C} \\
5\end{array}$ & $\begin{array}{c}\mathrm{I} \\
55\end{array}$ & $\begin{array}{c}\mathrm{C} \\
17\end{array}$ & $\begin{array}{c}\text { I } \\
192\end{array}$ & $\begin{array}{l}C \\
57\end{array}$ & $\begin{array}{c}\mathrm{I} \\
210\end{array}$ & $\begin{array}{l}\mathrm{C} \\
97\end{array}$ & $\begin{array}{c}\mathrm{I} \\
100\end{array}$ & $\begin{array}{l}C \\
56\end{array}$ \\
\hline \multirow{2}{*}{$\begin{array}{l}\text { Encontrar } \\
\text { dificultades } \\
\text { para recibir } \\
\text { ayuda de los/ } \\
\text { las docentes }\end{array}$} & \multicolumn{2}{|c|}{$165(20.3 \%)$} & \multicolumn{2}{|c|}{$283(34.9 \%)$} & \multicolumn{2}{|c|}{$261(32.1 \%)$} & \multicolumn{2}{|c|}{$65(8 \%)$} & \multicolumn{2}{|c|}{$36(4.4 \%)$} \\
\hline & $\begin{array}{c}\mathrm{I} \\
94\end{array}$ & $\begin{array}{c}C \\
71\end{array}$ & $\begin{array}{c}\text { I } \\
189\end{array}$ & $\begin{array}{l}C \\
94\end{array}$ & $\begin{array}{c}\text { I } \\
207\end{array}$ & $\begin{array}{c}C \\
54\end{array}$ & $\begin{array}{c}\mathrm{I} \\
55\end{array}$ & $\begin{array}{l}\mathrm{C} \\
10\end{array}$ & $\begin{array}{c}\text { I } \\
33\end{array}$ & $\begin{array}{l}\mathrm{C} \\
3\end{array}$ \\
\hline
\end{tabular}

Tabla 8. Ayudas y apoyos en el centro. género y manifestar que han recibido durante los primero años de carrera un trato injusto po razón de género. Estos datos refrendarían lo obtenidos en otros estudios (Erwin y Maurutto 1998; Rodd y Bartholomew, 2006) en los que las alumnas de estudios científicos manifestaban sentirse invisibles o ser tratadas de maner desigual por determinados profesores: no escucha de sus respuestas, descripción como mejo alumno de la clase referida a un varón a pesa de que el resultado académico más brillante sea el de una chica, profesores que se desplazan por el aula únicamente hacia el lugar ocupado po los chicos, la preconcepción de que la capacidad de las alumnas es innatamente menor, etc. Además, estos comportamientos son mucho más frecuentes en las carreras de tipo científico tecnológico -aquéllas en las que hemos centrado nuestro estudio- que en las del ámbito de la ciencias sociales o humanidades, en las que la presencia femenina tanto de docentes como de alumnas tiene una mayor trayectoria y que responde, en cierta medida, a la creencia "natural" de la habilidad de hombres y mujeres para según qué estudios.

Parece conveniente destacar que los estudiantes no perciben, al menos en la actualidad, que puedan existir interferencias entre el nive de exigencia de los estudios y sus responsabilidades familiares. Ésta será otra cuestión que convendrá explorar en la fase cualitativa de la investigación para corroborar si han hecho una estimación de la incidencia en el futuro o incluso, si esta negativa, sería el efecto directo de que en la actualidad no poseen ningún tipo de cargas familiares. En suma, sorprende que su percepción parece contradecir la denuncia de muchos de los estudios realizados sobre este tema, a saber, las dificultades para la conciliación y más particularmente en el caso de las mujeres (Bermúdez et al., 2011; Blättel-Mink, 2002; Donoso et al., 2011; Erwin y Maurutto 1998 ;Erwin y Stewart, 1997; Folch y Ramos, 2009; García-Gómez et al., 2009; Jackson, 2000 Alonso y Mas, 2009; Sax y Harper, 2007)

En el plano más propiamente pedagógico conviene resaltar los resultados referidos a un de los puntales de la variable denominada "per- suasión y apoyo social»: el soporte que creen poder recibir de docentes y tutores. En el caso de los docentes, aunque muchos de ellos consideran que las probabilidades de encontrarse a lo largo de sus estudios con «malos» docentes es importante, sin embargo, consideran mayoritariamente que no tendrán dificultades en conseguir ayuda de ellos en caso de necesitara. Convendría por tanto clarificar qué están entendiendo exactamente por malos docentes: aquellos cuyo nivel de exigencia es alto, profesores que resultan incomprensibles, docentes cuyas clases no resultan interesantes, etc. Sobre este particular, las respuestas de los estudiantes de ciencias resultan ligeramente más optimistas.

Finalmente, se concluye que un número importante de estudiantes desconoce la existencia de tutores, figura que quedaría enmarcada en Planes de Acción Tutorial que han incluido la mayoría de los centros en sus memorias de verificación para los nuevos Grados y que, aunque poco frecuente en el contexto español, tiene una larga trayectoria histórica en otros sistemas educativos. Esta desinformación preocupa de manera especial en tanto en cuanto más de la mitad del alumnado encuestado admite que tienen o considera que tendrá importantes dificultades de comprensión y por lo tanto, parece previsible que precisen algún tipo de apoyo extra como aprendices adultos.

\section{REFERENCIAS}

Alonso, A. V. y Mas, M. A. M. (2009). Patrones actitudinales de la vocación científica y tecnológica en chicas y chicos de Secundaria. Revista Iberoamericana de Educación, 50(4), 1-12. Recuperado enero 17, 2013 de http://www. rieoei.org/deloslectores/2950Vazquez.pdf.

Ayalon, H. (2003). Women and men go to University: mathematical background and gender differences in choice of field in Higher Education. Sex Roles, 48(5-6), 277-290.

Bandura, A., Barbaranelli, C., Caprara, G. y Pastorelli, C. (2001). Self-efficacy beliefs as shapers of children's aspirations and career trajectories. Child Development, 72(1), 187-206. 